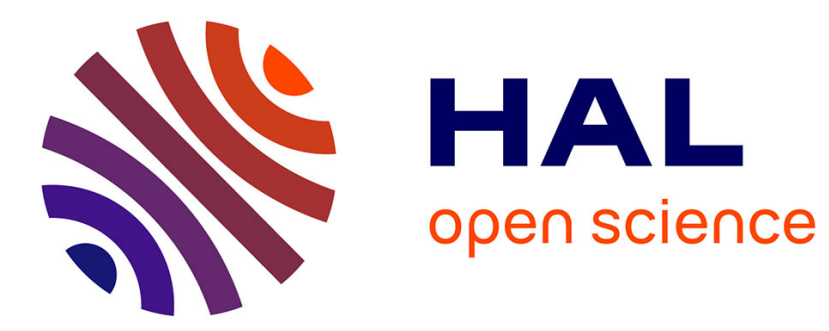

\title{
Screening for Al2O3 failure in MCrAlY APS coatings using short-term oxidation at high temperature
}

Damien Texier, Maxime Ecochard, Thomas Gheno, Daniel Monceau, Mehdi Salem, Philippe Lours

\section{- To cite this version:}

Damien Texier, Maxime Ecochard, Thomas Gheno, Daniel Monceau, Mehdi Salem, et al.. Screening for Al2O3 failure in MCrAlY APS coatings using short-term oxidation at high temperature. Corrosion Science, 2021, 184, pp.1-15/109334. 10.1016/j.corsci.2021.109334 . hal-03196688

\section{HAL Id: hal-03196688 https: //imt-mines-albi.hal.science/hal-03196688}

Submitted on 15 Apr 2021

HAL is a multi-disciplinary open access archive for the deposit and dissemination of scientific research documents, whether they are published or not. The documents may come from teaching and research institutions in France or abroad, or from public or private research centers.
L'archive ouverte pluridisciplinaire HAL, est destinée au dépôt et à la diffusion de documents scientifiques de niveau recherche, publiés ou non, émanant des établissements d'enseignement et de recherche français ou étrangers, des laboratoires publics ou privés. 


\title{
Screening for $\mathrm{Al}_{2} \mathrm{O}_{3}$ failure in MCrAlY APS coatings using short-term oxidation at high temperature
}

\author{
Damien Texier ${ }^{\mathrm{a}, *}$, Maxime Ecochard ${ }^{\mathrm{a}}$, Thomas Gheno ${ }^{\mathrm{b}}$, Daniel Monceau ${ }^{\mathrm{c}}$, Mehdi Salem ${ }^{\mathrm{a}}$, \\ Philippe Lours ${ }^{\mathrm{a}}$

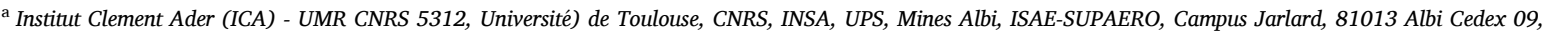 \\ France \\ b DMAS, ONERA, Université Paris Saclay, 92322 Chatillon, France \\ ${ }^{\text {c }}$ CIRIMAT, Université de Toulouse, CNRS, INPT, UPS, ENSIACET, 4 allée Emile Monso BP-44362, 31030, Toulouse Cedex 4, France
}

Keywords:

Oxidation

MCrAlY coating

Isothermal oxidation

Ultrathin samples

Reservoir effect

Breakaway

\begin{abstract}
A B S T R A C T
The high temperature oxidation behavior of an APS processed $\gamma-\beta$ NiCoCrAlY coating was investigated at 1150 ${ }^{\circ} \mathrm{C}$. Ultrathin freestanding coating specimens ranging from 16 to $240 \mu \mathrm{m}$ in thickness were tested for short-term oxidation time $(<300 \mathrm{~h}$ ). Intrinsic chemical failure ( $\mathrm{InCF}$ ) occurred after the full consumption of $\mathrm{Al}$, and resulted in $\mathrm{Cr}_{2} \mathrm{O}_{3}$ growth and $\mathrm{CrN}$ precipitation at the $\mathrm{Al}_{2} \mathrm{O}_{3}$ /alloy interface. Mass gain slowed down after InCF, even leading to a mass loss associated with the volatilization of $\mathrm{Cr}_{2} \mathrm{O}_{3}$. InCF occurred after [10-20] $\mathrm{h}$ and [20-100] $\mathrm{h}$ for the $\sim 21 \mu \mathrm{m}$ and $\sim 31 \mu \mathrm{m}$-thick specimens, respectively. Severe metal recession was observed after InCF.
\end{abstract}

\section{Introduction}

Nickel-based superalloys are widely used in the hot sections of turbomachines for aerospace and power plant applications. Their excellent mechanical properties at high temperatures and their good resistance to oxidizing and corrosive environments make them an ideal candidate for high temperature structural applications [1-3]. However, their surface reactivity at high temperature can be a limiting factor, especially with the increase in turbine inlet temperature and the severity of thermal cycling. MCrAlY (where $\mathrm{M}=\mathrm{Ni}$, $\mathrm{Co}$ or $\mathrm{Ni} / \mathrm{Co}$ ) or aluminide coatings are commonly used in the hottest parts of the turbines to protect the superalloy [4-6]. At temperatures above $\sim 1000{ }^{\circ} \mathrm{C}$, MCrAlY coatings develop a slow-growing, compact and adherent $\alpha-\mathrm{Al}_{2} \mathrm{O}_{3}$ scale, which provides the required protection $[7,8]$. However, their oxidation resistance can be a limiting factor due to the limited thickness of coatings, i. e., the "reservoir" of $\mathrm{Al}$ to form the protective $\alpha-\mathrm{Al}_{2} \mathrm{O}_{3}$ scale.

MCrAlY overlay coatings can be deposited using various line-of-sight or non-line-of-sight deposition processes depending on the geometrical complexity of the component to be coated. Extensive usage of projection processes makes some of these deposition techniques affordable and MCrAlY coatings have thus demonstrated a very interesting trade-off between a low-cost process and excellent protection for various industrial applications [9]. MCrAlY coatings are widely applied to first and second stage turbine blades and nozzle guide vanes, compressors, turbine shrouds, and turbine blades, i.e., for components exceeding $850^{\circ} \mathrm{C}$. Ever-more severe operating conditions are increasingly critical for the materials that are used, as cyclic loading promotes mechano-chemical coupling and the onset of early strain- and oxidation-assisted damage and cracking at the microstructure scale [10-14]. Repeated through-thickness cracking and/or spallation of the protective $\mathrm{Al}_{2} \mathrm{O}_{3}$ scale can bring the local $\mathrm{Al}$ concentration down to a critical-healing level for which reforming $\mathrm{Al}_{2} \mathrm{O}_{3}$ would no longer be possible $[15,16]$. This mechanism associated with change in oxidation products due to thermal and/or mechanical cracking of the protective oxide scale is termed Mechanically Induced Chemical Failure (MICF). Below the critical Al concentration, $\mathrm{Al}_{2} \mathrm{O}_{3}$ failure results in the rapid growth of oxides of the base elements (Ni, Co) $[17,18,8]$. This local change in oxidation behavior is highly detrimental for the integrity of the bond-coat itself. The occurrence of this localized breakaway can concomitantly be accelerated by coating-thick $\mathrm{Al}$ depletion due to interdiffusion with the underlying alloy $[19,20,8]$.

In components for which weight is of concern, MCrAlY coatings can be as thin as tens of micrometers. During prolonged exposure, oxidationinduced depletion can then extend to the whole coating section, to a point where the $\mathrm{Al}$ reservoir is fully consumed and $\mathrm{Al}_{2} \mathrm{O}_{3}$ is no longer the most stable oxide in contact with the metal. Failure of the protective

\footnotetext{
* Corresponding author.

E-mail address: damien.texier@mines-albi.fr (D. Texier).
} 
oxide in this case has been called "intrinsic chemical failure (InCF)" by Evans [16]. It is usually accompanied by an abrupt acceleration of the mass gain, associated with the growth of base metal oxides $[21,22,18$, $12,16,23-25]$, in a process termed generalized breakaway. In some cases, however, if the protective scale is mechanically intact, its chemical failure can lead to the slow growth of the next most stable oxide $\left(\mathrm{Cr}_{2} \mathrm{O}_{3}\right.$ in the case of (Al,Cr)-rich materials) at the alloy/scale interface, with kinetics limited by diffusion across the initial scale $[16,23,24]$. This can extend the coating lifetime before breakaway eventually occurs.

Localized and generalized breakaway are highly detrimental to the integrity of the bond-coat and underlying alloy, and even more damaging in thermal barrier coating (TBC) systems, where the bondcoat is overlaid with a thermal-insulating ceramic topcoat $[26,27]$. In TBCs, fast oxide growth at the bond-coat/top-coat interface may cause the top-coat to spall, thereby exposing the metal parts to excessive temperatures. The investigation of breakaway events, especially generalized breakaway, normally requires very-long-term exposure at high temperature (thousands of hours). A method for fast screening of breakaway events would be useful to accelerate materials development in association with numerical simulations [28]. Experimental testing can be accelerated using ultrathin specimens, with thicknesses comparable with the diffusion length of the alloying elements, i.e., in the order of tens of micrometers.

In the present study, oxidation experiments were performed at 1150 ${ }^{\circ} \mathrm{C}$ on ultrathin freestanding NiCoCrAlY coating specimens prepared with a dedicated precision jig [29]. InCF, i.e., the necessary condition for further generalized breakaway, was observed in hours in the thinnest specimens due to through-thickness $\mathrm{Al}$ depletion. Interrupted oxidation tests were performed to document the onset and progression of the generalized breakaway as a function of the exposure time. Thermogravimetric analyses were conducted to study the mass variation associated with the formation of the oxidation products. X-ray diffraction, chemical and metallographic analyses were carried out to identify the oxidation products in relation with the composition of the metal substrate.

\section{Materials and experimental procedures}

\subsection{Material and specimen preparation}

MCrAlY coatings used in the present study were prepared by air plasma spray (APS) deposition process by PRAXAIR $\odot$ research laboratory. The NiCoCrAlY powder was the commercial NI-191-4 powder from PRAXAIR $\odot$ [30]. The size distribution of the NiCoCrAlY powder is centered at $45 \pm 16 \mu \mathrm{m}$ (spherical particles). The powder composition is reported in Table 1 . The coating was initially deposited on a 304 stainless steel plate with dimensions of $50 \times 250 \times 2 \mathrm{~mm}^{3}$. No surface treatment was applied on the 304 stainless steel plate to favor natural debonding of the NiCoCrAlY coating from this substrate plate during the deposition process. Indeed, substantial strains generated by the APS process of thick coating resulted in the coating delamination during the deposition process, leading to 550-650 $\mu \mathrm{m}$ thick freestanding NiCoCrAlY plates. Then, $50 \times 25 \mathrm{~mm}^{2}$ samples were cut from the freestanding NiCoCrAlY coating and subjected to a standard heat treatment under air: $8 \mathrm{~h}$ at $1080^{\circ} \mathrm{C}$ followed by $20 \mathrm{~h}$ at $870^{\circ} \mathrm{C}$. The metallurgical state of the APS coating after this standard heat treatment is hereafter denoted "as-received" ("AR") microstructure in the present paper. This standard heat treatment is generally applied for improving the coating adhesion onto Ni-based superalloy substrates due to chemical

Table 1

Nominal composition of the NI-191-4 powder used to deposit the NiCoCrAlY coating [30] (in \%(at) and \%(wt))

\begin{tabular}{llllll}
\hline Element & $\mathrm{Ni}$ & $\mathrm{Co}$ & $\mathrm{Cr}$ & $\mathrm{Al}$ & $\mathrm{Y}$ \\
\hline$x_{i}$ (at.\%) & Balance & 18.8 & 16.5 & 23.0 & 0.3 \\
$w_{i}$ (wt.\%) & Balance & 22.0 & 17.0 & 12.3 & 0.5 \\
\hline
\end{tabular}

interdiffusion and for optimization of the mechanical properties of the Ni-based superalloy substrates [31]. Despite the use of freestanding coating samples in the present paper, this heat-treatment was performed to investigate the oxidation behavior of the industrially used metallurgical state and microstructure of the NiCoCrAlY APS coating. The "AR" microstructure of the APS processed NiCoCrAlY coating consists in a fine $\gamma / \beta$ microstructure with a $41 \% \gamma-59 \% \beta$ surface fraction proportion (obtained with image analyses on backscattered electron (BSE) images). Typical features of sprayed materials are observed, i.e., melted and resolidified powder particles (MRPP), un-melted powder particle (UMPP), pores, $\mathrm{Al}_{2} \mathrm{O}_{3}$ dispersoids and $\mathrm{AlN}$ precipitates located in the intersplat regions. AlN precipitates were found in a larger proportion compared to $\mathrm{Al}_{2} \mathrm{O}_{3}$ dispersoids. Samples for oxidation testing were cut with a precision cutting machine to the final dimensions $10 \times 15 \mathrm{~mm}^{2}$. They were then thinned using a custom precision jig and $\mathrm{SiC}$ papers down to a P4000 grit, to a final thickness of either $21 \pm 3,31 \pm 3,59 \pm 3$, $90 \pm 3$ or $238 \pm 3 \mu \mathrm{m}$. Five samples were prepared for each thickness range (that is, 25 samples in total). The sample thicknesses will be referred to as " $\sim \mathrm{XX} \mu \mathrm{m}$ " for samples with a thickness of $\mathrm{XX} \pm 3 \mu \mathrm{m}$. The thickness variation along each specimen was about $\pm 2-3 \mu \mathrm{m}$. The polishing procedure is described in detail in Ref. [29]. The sample thicknesses are comparable with the diffusion length of the alloying elements in the metal after relatively short exposure times $(\leq 300 \mathrm{~h})$ at $1150{ }^{\circ} \mathrm{C}$. The samples were cleaned with acetone and ethanol. The thicknesses were measured using a micrometer with an uncertainty of $\pm 1 \mu \mathrm{m}$, and weights were measured with a precision balance (Sartorius MC5), with an uncertainty of $\pm 1.0 \times 10^{-6} \mathrm{~g}$. Each specimen was photographed using a calibrated binocular magnifying glass (Leica DMS 300) to measure the sample surface, $S$, necessary to determine the evolution of the specific mass $\Delta m(t) / S$.

\subsection{Oxidation testing}

Two types of oxidation experiments were performed, both at 1150 ${ }^{\circ} \mathrm{C}$ : (i) thermogravimetric analysis (TGA) was used to continuously record mass variations, and (ii) an interrupted furnace test was used to observe local changes in the oxidation behavior associated with mass variation. TGA tests were performed for 300 hours using a Setaram Setsys balance. The sample was suspended using a platinum wire. These tests were interrupted once at $150 \mathrm{~h}$ to observe the sample surface. They were conducted under either static or flowing air, in order to evaluate the effect of air and oxygen replenishment on the oxidation kinetics.

The interrupted furnace test was conducted in a Nabertherm N 11/H furnace in laboratory air (static air) for a cumulative time of up to 500 hours. The specimens were hung on alumina supports using holders made of platinum wire. The specimens were weighed and their surface observed by optical and scanning electron microscopy periodically (after 5, 10, 15, 20, 50, 100, 150, 250, 350, and 500 h). Some were removed from the test at an interruption and used for X-ray diffraction (XRD) and cross-sectional observations using scanning electron microscopy (SEM).

\subsection{Microstructural and oxidation product analyses}

Surface and cross-sectional observations of the oxidized samples were conducted using optical microscopy (OM) and scanning electron microscopy (SEM) in backscattered electron mode. Based on the optical semi-transparency of the $\alpha-\mathrm{Al}_{2} \mathrm{O}_{3}$ scale in the visible spectrum, optical microscopy aimed to investigate potential change in oxidation products at the surface and/or at the $\alpha-\mathrm{Al}_{2} \mathrm{O}_{3} /$ metal interface. In contrast, $\alpha-\mathrm{Al}_{2} \mathrm{O}_{3}$ being opaque to electrons, solely surface observations could be conducted using scanning electron microscopy (SEM). In this study, SEM observations were conducted with a tabletop SEM Hitachi TM 3030 Plus for routine analyses of the external surface between interrupted oxidation tests, a Nova NanoSEM 450 field-emission gun SEM (FEG-SEM) from Thermo Fischer Scientific and a JSM 7800F Prime FEG-SEM from 
JEOL for cross-sectional observations. Ten cross-sectional micrographs were taken for each thickness/exposure duration variants with the same SEM operating conditions (tension $=10 \mathrm{keV}$, probe current $=1.5 \mathrm{nA}$, working distance $=6 \mathrm{~mm}$ ) for image analyses using Fiji software [32] to segment the different oxides in presence and their thickness evolution. The Nova NanoSEM 450 FEG-SEM was equipped with a GENESIS APEX $2 \mathrm{i}$ EDS detector from EDAX for chemical profiles and mapping. Focused ion beam (FIB) cross-sectional preparations and observations were performed using a Dual-Beam FEG-SEM HELIOS 600i from Thermo Fischer Scientific equipped with a SDD X-Max $80 \mathrm{~mm}^{2}$ detector and EDX Aztec Advanced (Oxford Instruments).

\subsection{X-Ray diffraction analyses}

X-Ray Diffraction (XRD) analyses of the oxidized samples were performed with a diffractometer X'Pert PANALYTICAL from Philips using a Cu-K $\alpha$ radiation $(\lambda=1.54 \AA$ ) for the identification of crystallographic structure of the oxides. X-ray scans were carried out in a range of angles $(2 \theta)$ from $15^{\circ}$ to $100^{\circ}$ with a step size of $0.033^{\circ}$ and an acquisition time per step of $200 \mathrm{~s}$ (linear detector with a range of $2 \theta=2.1^{\circ}$ ).

\section{Results}

\subsection{High temperature oxidation kinetics}

Furnace tests and TGA were performed on NiCoCrAlY APS freestanding coating samples with different thicknesses ranging from 24 to $238 \mu \mathrm{m}$ at $1150^{\circ} \mathrm{C}$ during $300 \mathrm{~h}$. The mass gain is plotted as a function of the time for both types of oxidation tests in Fig. 1(a). The $227 \mu \mathrm{m}$-thick sample oxidized under air flow is considered as a reference sample since it was not subject to InCF in the investigated time range. The mass variation, $\Delta m(t) / S$, of the reference sample progressively increased up to $1.3 \mathrm{mg} \cdot \mathrm{cm}^{-2}$ after $300 \mathrm{~h}$. A log-log representation of the mass gain evolution is given in Fig. 1(b) to analyze the oxidation kinetics based on a $n^{\text {th }}$ root rate law, i.e., a power rate law with exponent $1 / n$. During the first $2.5 \mathrm{~h}$ of oxidation, the $227 \mu \mathrm{m}$-thick sample followed nearly parabolic kinetics $(n \approx 2)$. The mass variation then deviated from a parabolic behavior and the exponent stabilized at $n=3.9$. The reasons underlying this change in oxidation kinetics will be discussed in Section 4 . As will be shown, both short-term and long-term oxidation kinetics can be described using a single logarithmic rate law. The $238 \mu \mathrm{m}$-thick sample oxidized using furnace tests follows a $n^{\text {th }}$ root rate law with $n=2.4$. Some variability in oxidation kinetics was noticed for furnace tests.

TGA and furnace tests were also conducted on ultrathin samples, i.e., on volume-limited samples, to trigger InCF. For the $29 \mu \mathrm{m}$-thick sample oxidized under air flow (light blue curve in Fig. 1), the mass gain was very similar to the reference behavior during the first [15-30] h. After this period, the mass gain progressively slowed down up to $100 \mathrm{~h}$ to reach a maximal value of $0.85 \mathrm{mg} \cdot \mathrm{cm}^{-2}$. Assuming that only $\mathrm{Al}_{2} \mathrm{O}_{3}$ formed in the first stage of oxidation, the mass variation of $\mathrm{Al}, \Delta m_{\mathrm{Al}}(t)$, can be expressed as:

$2 \mathrm{Al}+\frac{3}{2} \mathrm{O}_{2} \longrightarrow \mathrm{Al}_{2} \mathrm{O}_{3}$

$\frac{\Delta m_{\mathrm{Al}}(t)}{S}=\frac{2}{3} \frac{M_{\mathrm{Al}}}{M_{\mathrm{O}}} \frac{\Delta m(t)}{S}$

with $\Delta m(t)$, the recorded mass gain corresponding to the oxygen uptake, $M_{\mathrm{Al}}$, the molar mass of aluminum, $M_{\mathrm{O}}$, the molar mass of oxygen, and $S$, the sample surface. The maximal value of the mass gain $\left(0.85 \mathrm{mg} \cdot \mathrm{cm}^{-2}\right)$, if only attributed to the addition of oxygen to form the $\mathrm{Al}_{2} \mathrm{O}_{3}$ scale, corresponds to the consumption of $106 \%$ of the $\mathrm{Al}$ content initially present in the $29 \mu \mathrm{m}$-thick sample. Furthermore, a decrease in mass was observed for exposure times longer than $100 \mathrm{~h}\left(0.60 \mathrm{mg} \cdot \mathrm{cm}^{-2}\right.$ at $290 \mathrm{~h}$, i.e., a decrease of $29.5 \%$ of the maximal mass gain for this sample). Similar behaviors were observed for thin and thick samples using static air furnace tests. However, no apparent mass loss was measured using discontinuous weight measurements under static air. A stabilization of the mass gain was observed for samples with a thickness of $24 \mu \mathrm{m}$ and 33 $\mu \mathrm{m}$. Similar to the ultrathin TGA sample, the maximum mass gain corresponds to the whole consumption of $\mathrm{Al}$ to form $\mathrm{Al}_{2} \mathrm{O}_{3}$. A TGA test using static air was conducted on a $16 \mu \mathrm{m}$-thick sample for comparison with the furnace tests (dark blue curve in Fig. 1). During the first tens of hours, the oxidation behavior of the sample was similar to the one of samples tested under air flow condition. However, a stabilization of the mass gain (or even a slight increase) is observed when $100 \%$ of the $\mathrm{Al}$ of the sample is oxidized. It is worth reminding that mass loss was observed for the ultrathin sample tested under air flow (light blue curve in Fig. 1) once $100 \%$ of the $\mathrm{Al}$ content of the sample was oxidized.

\subsection{Surface observations at different exposure times}

Optical macrographs of the sample surface are presented in Fig. 2. Samples thicker than $61 \mu \mathrm{m}$ present a homogeneous light gray surface, typical of an external $\mathrm{Al}_{2} \mathrm{O}_{3}$ scale. Some oxide spallation (bright spots on the sample surface) is observed due to cooling at each interruption. In contrast, darker gray regions are observed for 24 to $33 \mu \mathrm{m}$-thick samples in this time window. This variation in optical properties is associated (a)

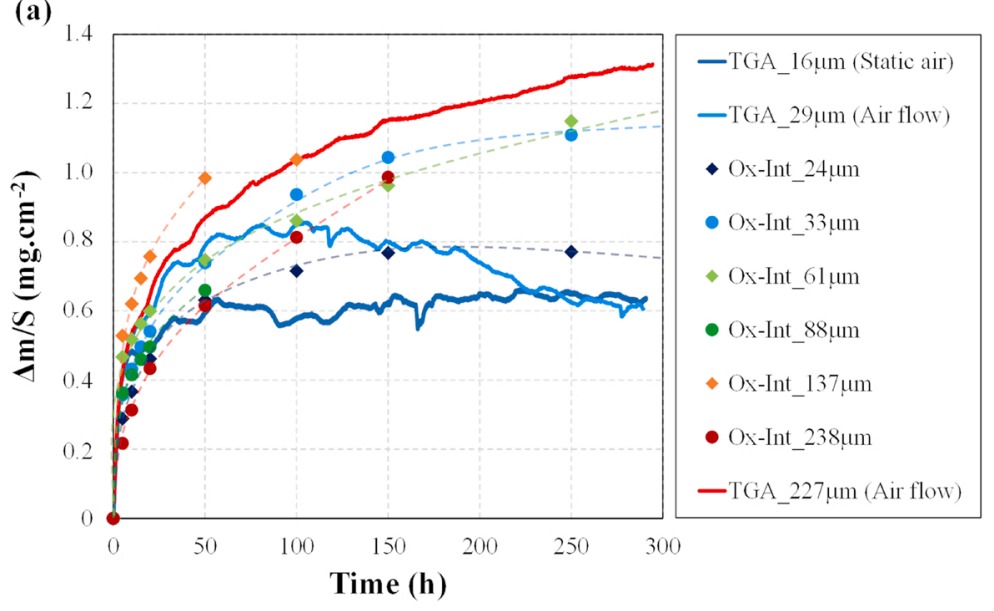

(b)

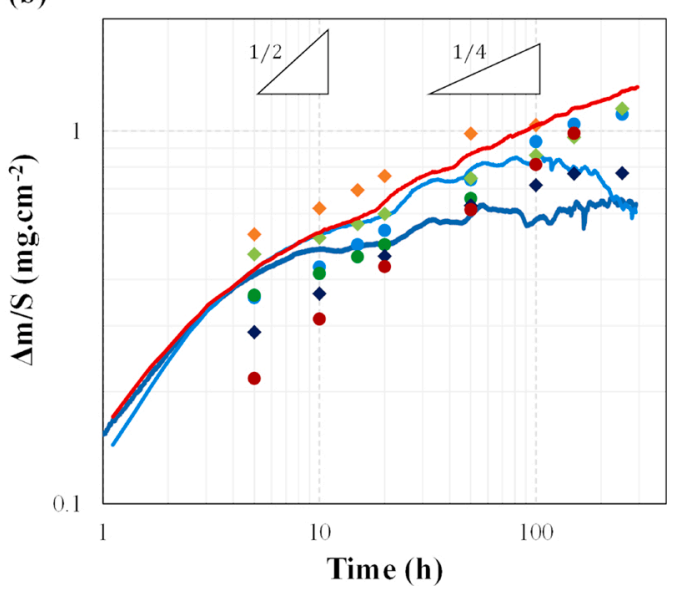

Fig. 1. (a) Mass gain evolution of a NiCoCrAlY APS freestanding coating samples with different thicknesses ranging from 24 to $238 \mu \mathrm{m}$. Solid lines correspond to TGA tests conducted on the thinnest and thickest samples. Markers correspond to furnace tests and associated dashed lines are drawn for reading convenience, (b) Log-log representation of the mass gain evolution as a function of the time. 


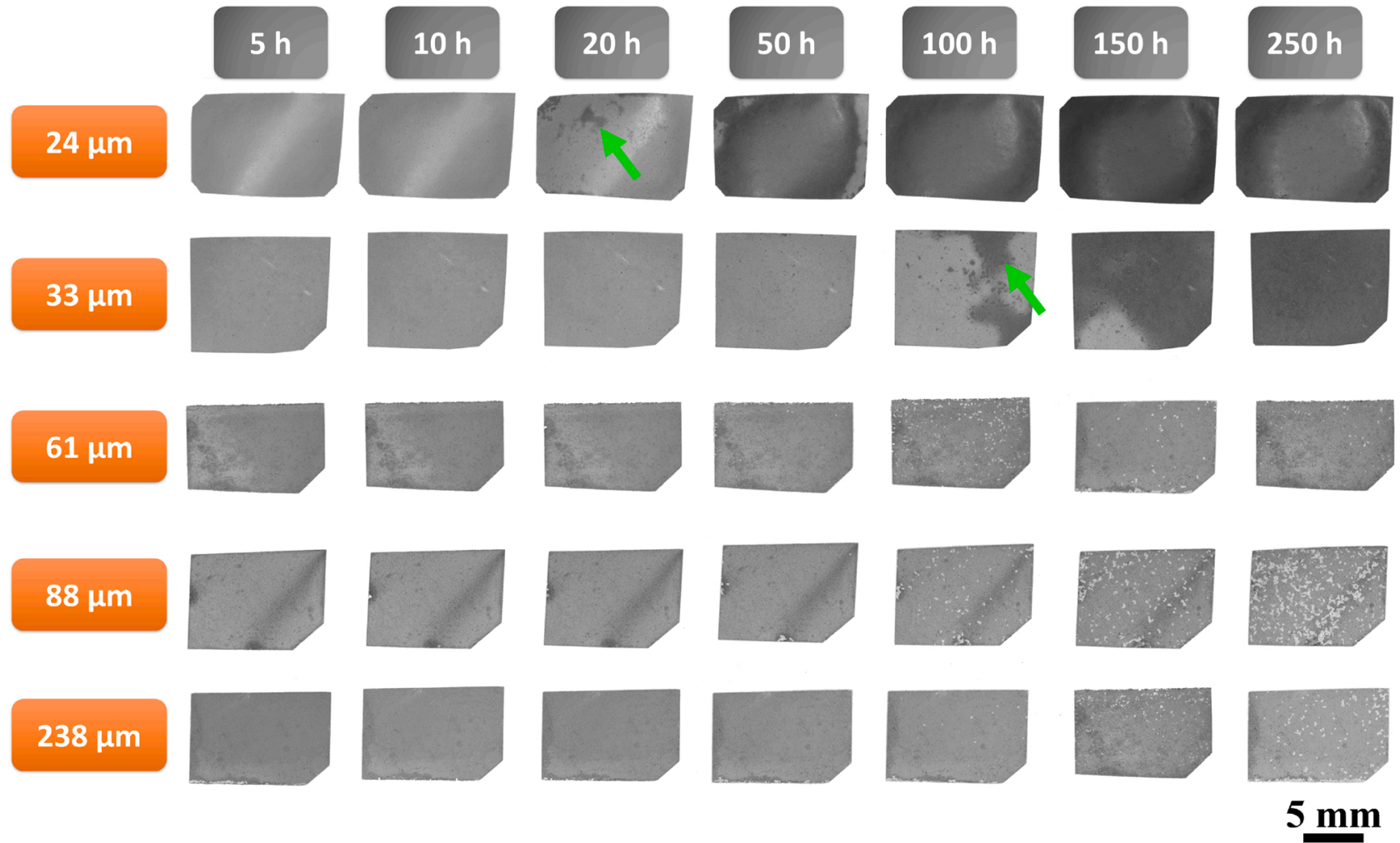

Fig. 2. Optical macrographs of oxidized samples with various thicknesses at different oxidation times showing InCF for samples thinner than $61 \mu \mathrm{m}$ (dark gray regions) and $\mathrm{Al}_{2} \mathrm{O}_{3}$ spallation for thicker samples (nearly white spots). The onset of InCF is highlighted with green arrows.

with the formation of a new reactive product forming in the oxide scale, related to InCF. The onset of InCF is visible after $20 \mathrm{~h}$ oxidation in the thinner sample (green arrow). The regions experiencing InCF then spread to fully cover the sample surface between 50 and $100 \mathrm{~h}$. For the $33 \mu \mathrm{m}$-thick sample, InCF is visible after $100 \mathrm{~h}$ oxidation (green arrow) while the full extension occurred between 150 and $250 \mathrm{~h}$. It is worth noting that InCF did not always start from the sample edges.

Image analysis of the macrographs aimed to measure the surface fraction of the InCF-affected region on both faces of the samples as a function of time (Fig. 3(a)). Samples with a thickness of $\sim 21 \mu \mathrm{m}$ demonstrate a sharp transition from $\mathrm{Al}_{2} \mathrm{O}_{3}$ growth to generalized InCF, while the transition extends over a longer period in the $\sim 31 \mu \mathrm{m}$-thick samples. When correlating the surface fraction of the sample affected by
InCF with the associated mass gain (Fig. 3 (b)), a similar trend is found regardless of the sample thickness. The onset of InCF is observed when $60-70 \%$ of the aluminum is consumed from the MCrAlY alloy to form the oxide. Interestingly, all the samples are fully affected by InCF when all the aluminum from the alloy is consumed to form the oxide layer.

\subsection{Surface observations of the oxidized samples before and after InCF}

The sample surfaces were examined using SEM in order to identify the oxides present before and after InCF. Fig. 4 shows images recorded to this effect, on a $61 \mu \mathrm{m}$ - and $24 \mu \mathrm{m}$-thick samples after $100 \mathrm{~h}$. The $61 \mu \mathrm{m}$ thick sample is mainly covered by an external $\mathrm{Al}_{2} \mathrm{O}_{3}$ scale (dark gray region) with islets of mixed $\mathrm{Ni}-\mathrm{Co}-\mathrm{Al}$ oxide sparsely distributed on the
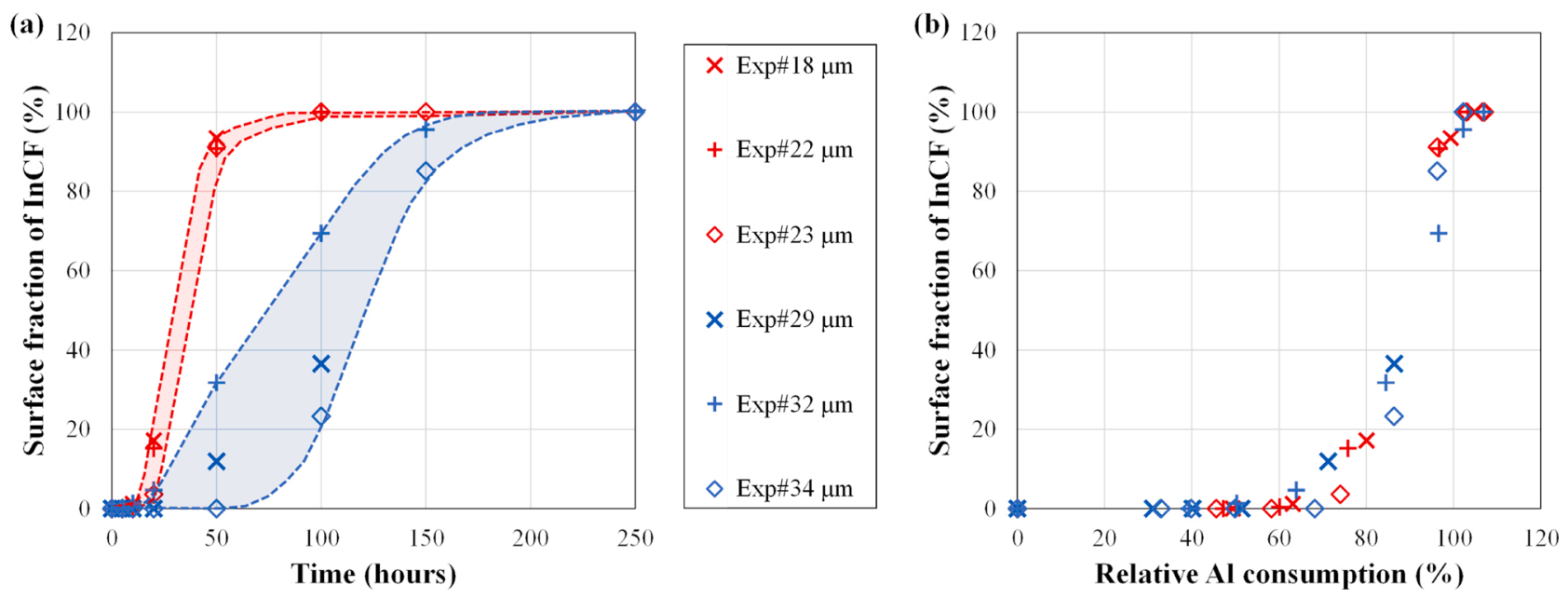

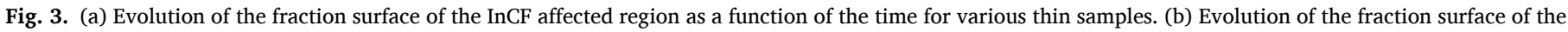
$\mathrm{InCF}$ affected region as a function of the relative aluminum consumption considering that the mass gain is attributed to the formation of exclusively $\mathrm{Al}_{2} \mathrm{O}_{3}$. 

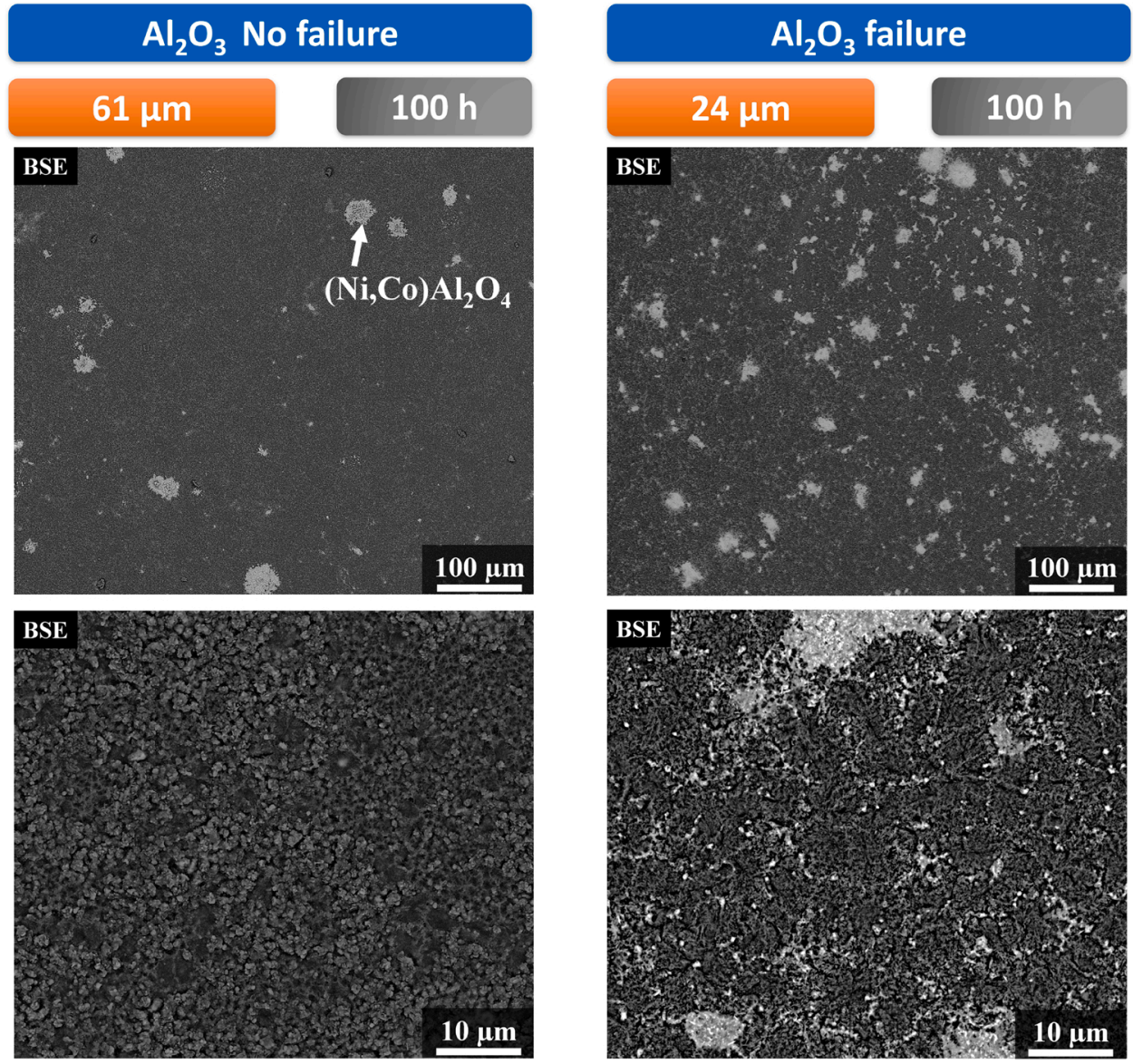

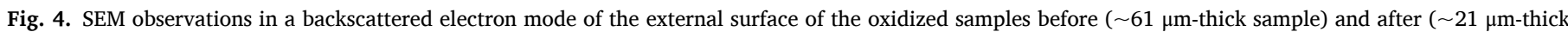
sample) InCF showing some islets of $(\mathrm{Ni}, \mathrm{Co}) \mathrm{Al}_{2} \mathrm{O}_{4}$ spinels and changes in the external oxide scale.

surface (light gray spots). Analysis by EDS (not shown here) showed that the composition of these mixed oxides is consistent with a $(\mathrm{Ni}, \mathrm{Co}) \mathrm{Al}_{2} \mathrm{O}_{4}$ spinel. The $24 \mu \mathrm{m}$-thick sample exhibits a greater surface fraction of spinels, and a network of ( $\mathrm{Ni}, \mathrm{Cr}, \mathrm{Co})$-rich oxides developed between these islets.

In addition, (Ni,Co)-rich oxides are also observed in the center of some islets of $(\mathrm{Ni}, \mathrm{Co}) \mathrm{Al}_{2} \mathrm{O}_{4}$ spinels for the $\sim 21 \mu \mathrm{m}$ - and $\sim 31 \mu \mathrm{m}$-thick samples after InCF (see e.g. Fig. 5(a) and (b)).

\subsection{X-ray diffraction analyses of the oxidized samples}

X-ray diffraction analyses were performed on oxidized samples with a thickness of $21 \pm 3,31 \pm 3$ and $238 \pm 3 \mu \mathrm{m}$ after cumulative oxidation exposures of 20, 50, 100 and $250 \mathrm{~h}$ (Fig. 6). The intensity of the XRD diagrams was normalized by the intensity of the $\gamma$-Ni peak corresponding to $\{111\}$ planes. The $\sim 238 \mu \mathrm{m}$-thick samples exclusively formed $\alpha-\mathrm{Al}_{2} \mathrm{O}_{3}$ at all time steps examined, with the relative intensity of the $\{104\} \mathrm{Al}_{2} \mathrm{O}_{3}$ peak gradually increasing with time. For the $\sim 21$ and $\sim 31$ $\mu \mathrm{m}$-thick samples, $\mathrm{Al}_{2} \mathrm{O}_{3}$ is observed for all the exposure durations and $\mathrm{Cr}_{2} \mathrm{O}_{3}$ is identified at $50 \mathrm{~h}$ and $100 \mathrm{~h}$, respectively. Neither (Ni,Co)-rich oxides nor $(\mathrm{Ni}, \mathrm{Co}) \mathrm{Al}_{2} \mathrm{O}_{4}$ spinels are identified after InCF on XRD diagrams owing to their sparse occurrence.

The ratio of intensity of the $\{104\} \mathrm{Al}_{2} \mathrm{O}_{3}$ peak (red curves) and $\{104\}$ $\mathrm{Cr}_{2} \mathrm{O}_{3}$ peak (blue curves) related to the $\{111\} \gamma$-Ni peak was calculated in order to qualitatively document the thickness evolution of the oxide scale (Fig. 7).

For the reference sample exclusively forming an $\mathrm{Al}_{2} \mathrm{O}_{3}$ scale, the relative intensity of the $\{104\} \mathrm{Al}_{2} \mathrm{O}_{3}$ peak increases with the exposure time with a trend very similar to the one of the mass gain evolution. For the $\sim 21 \mu \mathrm{m}$ - and $\sim 31 \mu \mathrm{m}$-thick samples, the relative intensity of the $\mathrm{Al}_{2} \mathrm{O}_{3}$ peak also increases with the exposure time with a different behavior compared to that of the reference sample. Prior to InCF, the relative intensity of the $\mathrm{Al}_{2} \mathrm{O}_{3}$ peak is similar to the one of the reference sample. However, the relative intensity of the $\mathrm{Al}_{2} \mathrm{O}_{3}$ peak progressively increases when $\mathrm{Cr}_{2} \mathrm{O}_{3}$ is formed. The increase of the $\mathrm{Al}_{2} \mathrm{O}_{3}$ peak after InCF does not necessarily signify a growth of the $\mathrm{Al}_{2} \mathrm{O}_{3}$ scale since the intensity of the $\mathrm{Ni}$ peak is weakened by the growth of the underlying $\mathrm{Cr}_{2} \mathrm{O}_{3}$ scale. The slope of the $\mathrm{Al}_{2} \mathrm{O}_{3}$ signal as a function of the exposure time is similar for both the $\sim 21 \mu \mathrm{m}$ - and $\sim 31 \mu \mathrm{m}$-thick samples when $\mathrm{Cr}_{2} \mathrm{O}_{3}$ is formed. The relative intensity of the $\mathrm{Cr}_{2} \mathrm{O}_{3}$ peak also increases with the time in a linear manner when InCF is observed.

\subsection{Cross-sectional analyses of the oxidized samples}

Cross-sectional observations of the $\sim 21 \mu \mathrm{m}$-thick samples oxidized during 20 and $50 \mathrm{~h}$ were conducted to document the evolution of the oxide scale and the underlying alloy microstructure before and after InCF. It is worth reminding that the "AR" sprayed NiCoCrAlY coating consisted in a $\gamma / \beta$ microstructure with AlN precipitates and $\mathrm{Al}_{2} \mathrm{O}_{3}$ dispersoids located in the bulk in intersplat regions. After $20 \mathrm{~h}$, most of the sample surface is not affected by InCF, as illustrated in Figs. 2 and 3 . In regions not affected by $\mathrm{InCF}$, an external $\mathrm{Al}_{2} \mathrm{O}_{3}$ scale exclusively forms, as shown on EDS maps in Fig. 8. Residual $\beta$-NiAl regions (Al-rich/Crpoor regions on EDS micrographs and medium gray regions on BSE micrographs) and AlN precipitates are observed in the bulk of the specimen, showing that the $\mathrm{Al}$ reservoir is not fully exhausted yet. After $50 \mathrm{~h}$, a continuous $\mathrm{Cr}_{2} \mathrm{O}_{3}$ layer (medium gray in BSE micrograph) has developed beneath the $\mathrm{Al}_{2} \mathrm{O}_{3}$ scale and no $\beta$-NiAl or AlN is left in the 
(a)

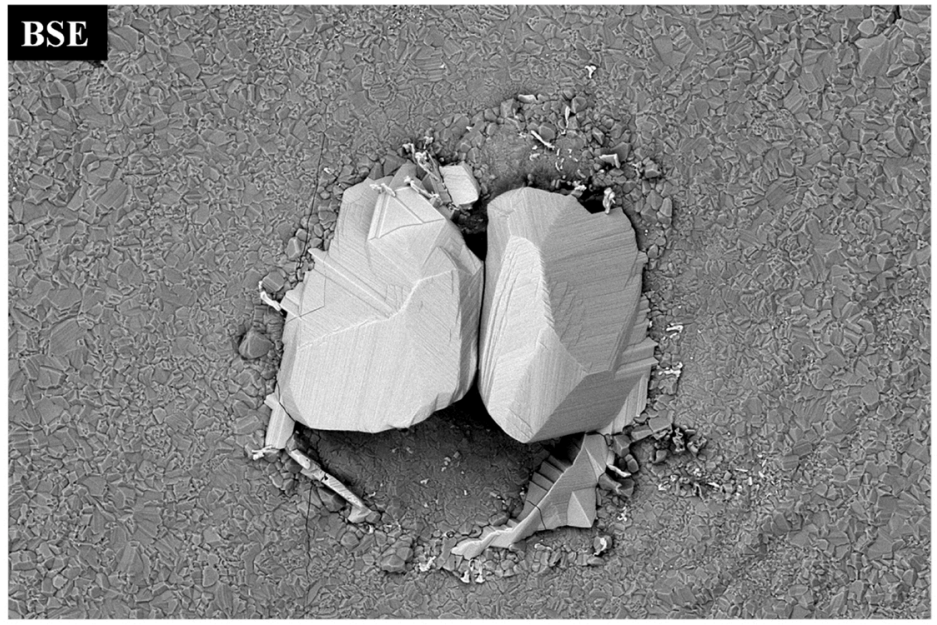

(b) BSE
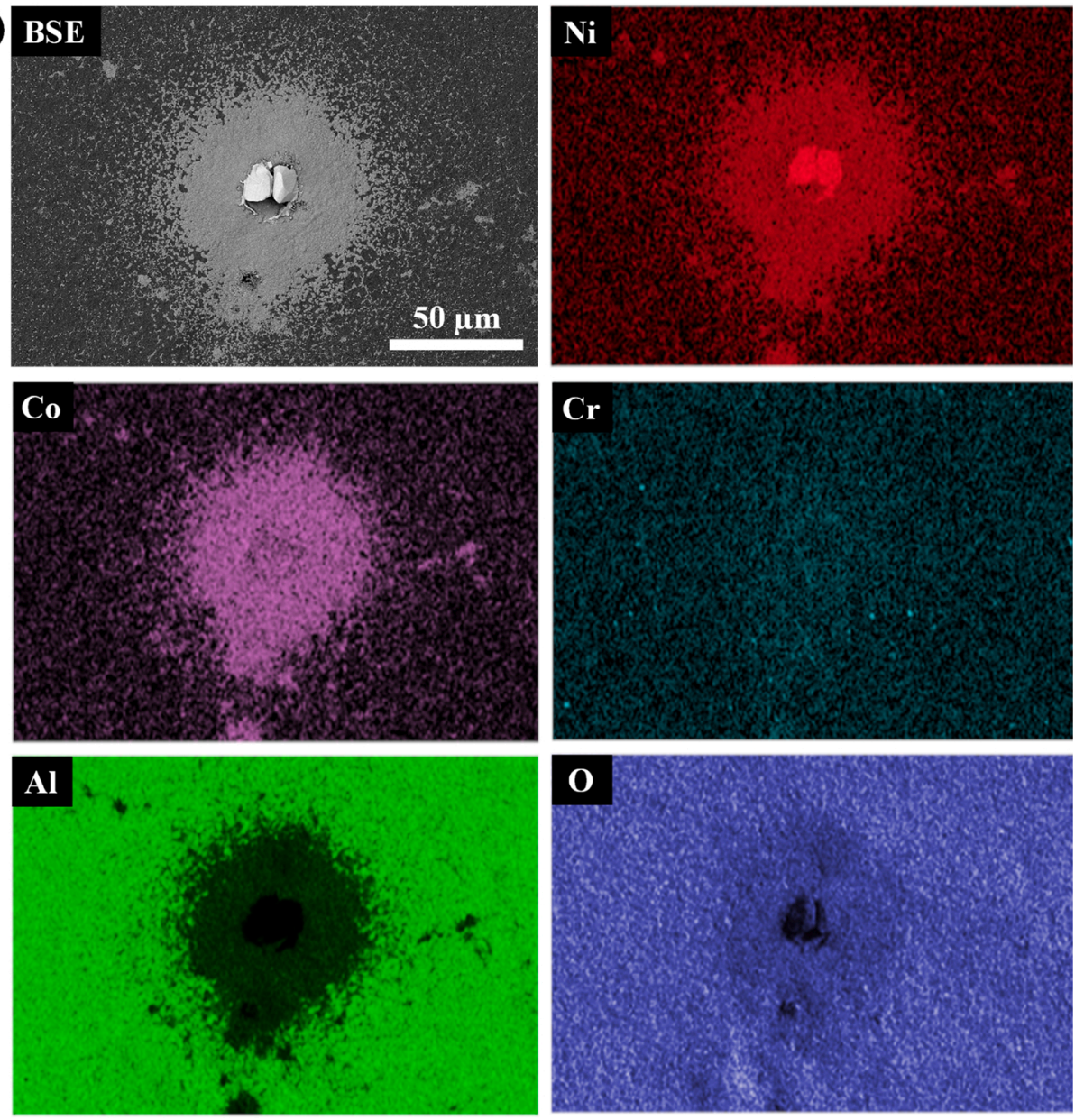

Fig. 5. Observation of ( $\mathrm{Ni}, \mathrm{Co}$ )-rich oxides as the final stage of the InCF growing on ( $\mathrm{Ni}, \mathrm{Co}) \mathrm{Al}_{2} \mathrm{O}_{4}$ islets after $100 \mathrm{~h}$ at $1150{ }^{\circ} \mathrm{C}$ for a $\sim 21 \mu \mathrm{m}$-thick sample. (a) Surface observation in backscattered electron mode, (b) Element maps on surface observations.

alloy. The $\mathrm{Cr}_{2} \mathrm{O}_{3}$ contains small amounts of $\mathrm{Al}$ detected using spot analyses in coarse $\mathrm{Cr}_{2} \mathrm{O}_{3}$ regions during EDS analyses (see EDS analysis in supplementary materials in "Supplementary note 4/Supplementary Table 3/p. 10"). In addition, chromium nitride precipitates are found sparsely distributed at the $\mathrm{Cr}_{2} \mathrm{O}_{3} /$ metal interface. The crystal structure of this nitride phase could not be identified, as it was not present in sufficient amounts to give visible signal in the diffractograms (Fig. 6). However, EDS analysis showed that its composition corresponds to the $\mathrm{CrN}$ compound (see supplementary materials). $\mathrm{Cr}_{2} \mathrm{O}_{3}$ as well as Y-rich oxide dispersoids are also observed in the bulk of the sample. Therefore, the darker regions evidenced from surface observations when InCF occurs correspond to the formation of the $\mathrm{Cr}_{2} \mathrm{O}_{3}$ scale plus $\mathrm{CrN}$ precipitates beneath the external $\mathrm{Al}_{2} \mathrm{O}_{3}$ scale (Fig. 2). The readers are referred to supplementary materials for additional EDS analysis of the oxide scale.

The evolution of the microstructure beneath the oxide scale and the composition of the oxide scale for each sample thickness ranging from 18 to $241 \mu \mathrm{m}$ was illustrated in Fig. 9. Micrographs of the $\sim 238 \mu \mathrm{m}$-thick samples clearly show no $\mathrm{Al}_{2} \mathrm{O}_{3}$ failure, i.e., the reference condition. The growth of the $\mathrm{Al}_{2} \mathrm{O}_{3}$ scale is accompanied by an extension of the $\beta$-NiAldepleted region with the exposure time, not affecting the sample core. As 

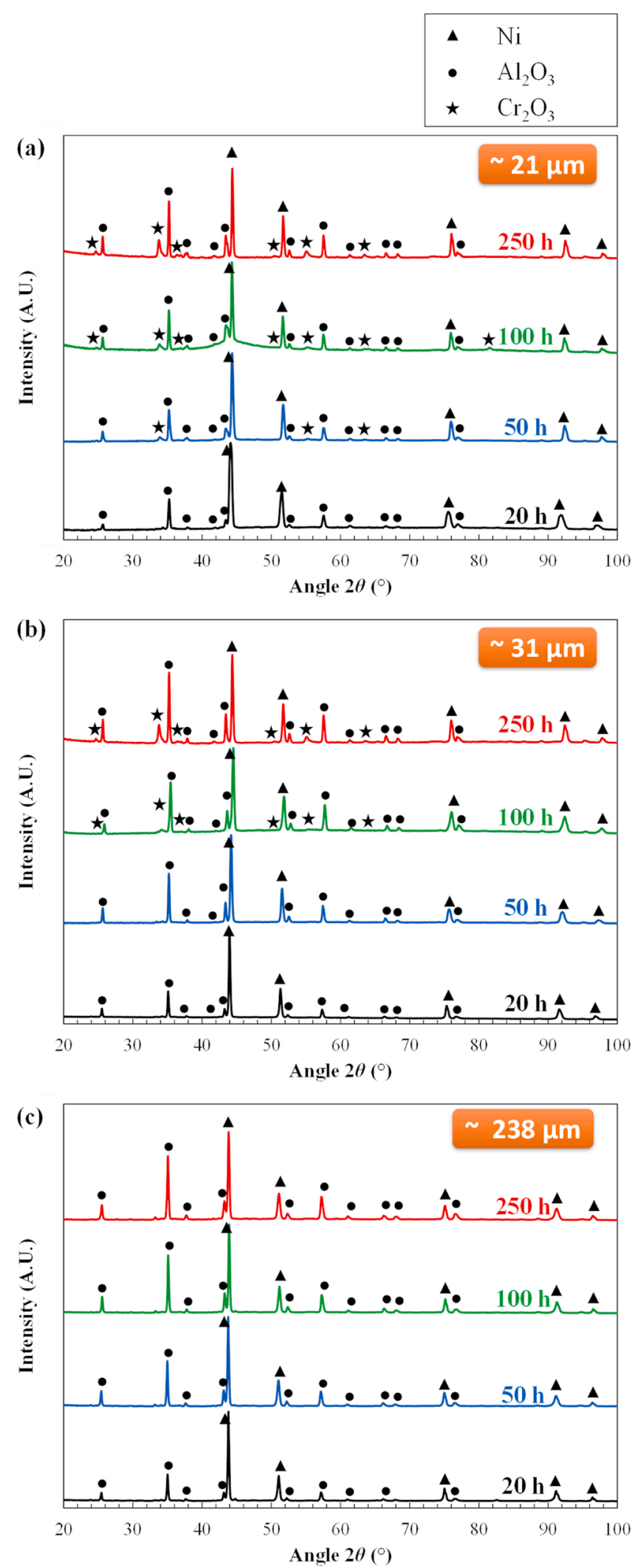

Fig. 6. XRD diagrams for samples with a thickness of (a) $\sim 21 \mu \mathrm{m}$, (b) $\sim 31 \mu \mathrm{m}$, and (c) $\sim 238 \mu \mathrm{m}$ oxidized during 20, 50, 100 and $250 \mathrm{~h}$. aforementioned, InCF occurs at shorter times for thinner samples. Interestingly, no trace of $\beta$ - $\mathrm{NiAl}$ was present in the remaining metallic material and no $\mathrm{Cr}_{2} \mathrm{O}_{3} / \mathrm{CrN}$ forms for the " $50 \mathrm{~h} / \sim 31 \mu \mathrm{m}$ " sample.

Analysis of the BSE micrographs aimed to quantitatively measure the evolution of oxide thicknesses but also the metal recession for several sample thickness-oxidation duration couples (Fig. 10). For the reference sample, i.e., the $\sim 238 \mu$ m-thick samples, the $\mathrm{Al}_{2} \mathrm{O}_{3}$ scale grew with a power law exponent of $n \approx 2.5$, which is lower than the one identified from mass gain data. For the $\sim 21 \mu \mathrm{m}$ - and $\sim 31 \mu \mathrm{m}$-thick samples, the growth of the $\mathrm{Al}_{2} \mathrm{O}_{3}$ scale is similar to the one of the reference samples as long as no $\mathrm{Cr}_{2} \mathrm{O}_{3}$ scale/CrN precipitate is observed. Once $\mathrm{Cr}_{2} \mathrm{O}_{3} / \mathrm{CrN}$ develops, the thickness of the $\mathrm{Al}_{2} \mathrm{O}_{3}$ scale stabilizes and even slightly decreases with the oxidation time. Furthermore, the $\mathrm{Cr}_{2} \mathrm{O}_{3} / \mathrm{CrN}$ scale was measured and its thickness was found to slightly decrease with the time after InCF occurrence, leading to a decrease of the overall external oxide scale thickness. In addition, the extent of metal recession is smaller than the $\mathrm{Al}_{2} \mathrm{O}_{3}$ thickness for all exposure times for the $\sim 238 \mu \mathrm{m}$-thick samples. It is worth noting that the extension of the metal recession is much greater than the growth of the $\mathrm{Al}_{2} \mathrm{O}_{3}$ scale after InCF for ultrathin samples.

\subsection{Chemical composition profiles before and after InCF}

Ten EDS profiles were performed for each oxidation condition to assess the evolution of the composition within the metallic material before and after InCF for the $\sim 21 \mu \mathrm{m}$-thick samples (Fig. 11). For information and comparison, the elemental composition of the $\gamma$ phase of the $20 \mathrm{~h}$ oxidation condition has been reported as dashed lines in Fig. 11, with colors corresponding to the different elements. After $20 \mathrm{~h}$, residual $\beta$-NiAl (Al-rich/Cr-poor regions) are observed in the bulk of the specimen, and InCF has not yet started. A slight gradient of composition is observed in the 2-3 $\mu \mathrm{m}$-thick region near the $\mathrm{Al}_{2} \mathrm{O}_{3}$-metal interface. For information, InCF was seen to occur between 20 and $50 \mathrm{~h}$ for the $\sim 21$ $\mu \mathrm{m}$-thick samples (see e.g. Fig. 3). After $50 \mathrm{~h}$ and longer, no $\beta$ is left and $\mathrm{Al}$ has been fully consumed. The $\mathrm{Cr}$ content is found to be minimal $(\approx 11$ $\%$ (at.) at $50 \mathrm{~h}$ while the reference concentration is about two times higher). This modification in $\mathrm{Cr}$ content is partly attributed to $\mathrm{Cr}_{2} \mathrm{O}_{3}$ and CrN when InCF occurs.

\subsection{FIB cross-section observation of local InCF: (Ni,Co)-rich oxides}

Focused ion beam (FIB)-cross sections of the (Ni,Co)-rich oxides located in islets of $(\mathrm{Ni}, \mathrm{Co}) \mathrm{Al}_{2} \mathrm{O}_{4}$ spinels were performed (Fig. 12). The contour of the external oxide has been marked with white dashed lines to differentiate FIB cross-sectional observations from surface observations on the tilted view. The morphology of the external oxide scale beneath the $(\mathrm{Ni}, \mathrm{Co})$-rich oxide observed on the FIB-cross section is quite complex, consisting of different layers: (1) the original and protective external $\mathrm{Al}_{2} \mathrm{O}_{3}$ scale, (2) intrusions of $\mathrm{Al}_{2} \mathrm{O}_{3}$ within the bulk due to the splat microstructure of the APS coating (see e.g. Ref. [33]), (3) the $\mathrm{Cr}_{2} \mathrm{O}_{3}$ layer growing after InCF, (4) $(\mathrm{Ni}, \mathrm{Co}) \mathrm{Al}_{2} \mathrm{O}_{4}$ spinels corresponding to the light gray oxide islets shown on the BSE surface observations, (5) $(\mathrm{Ni}$, Co)-rich oxides being the last stage of InCF observed in the present study, and (6) some remaining metallic regions. Such (Ni,Co)-rich oxides were only observed in regions presenting $\mathrm{Al}_{2} \mathrm{O}_{3}$ intrusion, i.e., severe intersplat oxidation.

\section{Discussion}

The motivation of the present paper was to predict general InCF of ultrathin samples using oxidation properties obtained on bulk samples of an $\mathrm{Al}_{2} \mathrm{O}_{3}$-forming MCrAlY alloy. Ultrathin samples with different thicknesses, i.e., with different aluminum reservoirs, were thus investigated in order to document the incubation time for the onset of the InCF. Testing ultrathin samples, i.e., thinner than $60 \mu \mathrm{m}$, was demonstrated to activate InCF in a reasonable time at operating temperatures (tens of 


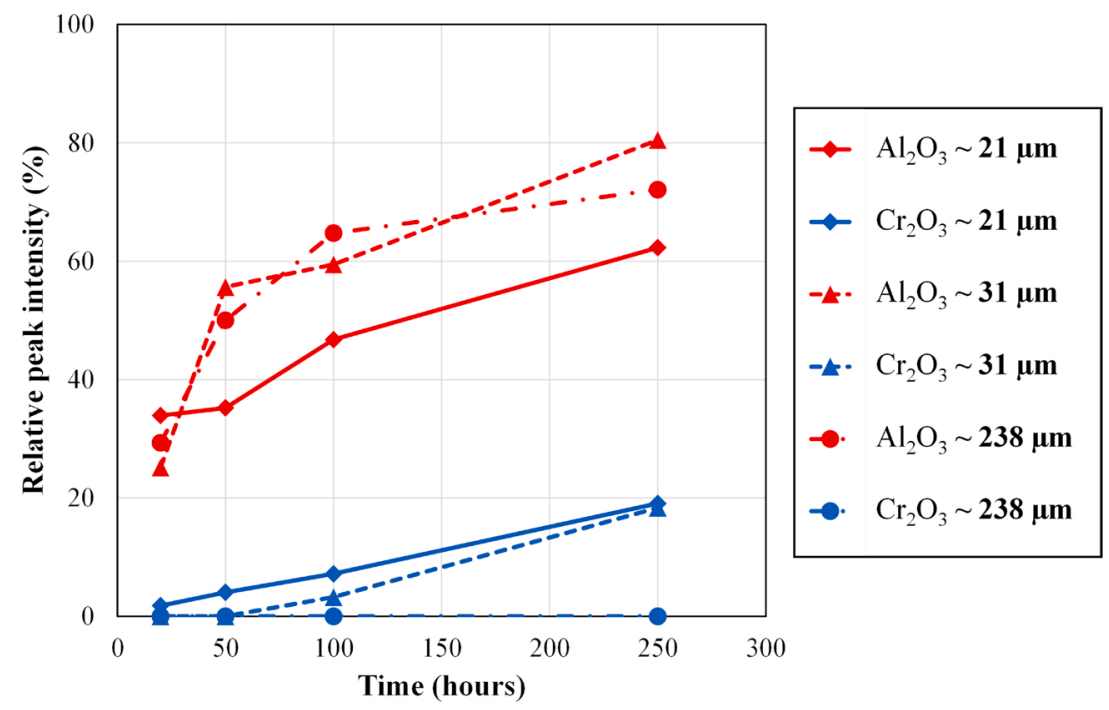

Fig. 7. Relative peak intensity of the $\alpha-\mathrm{Al}_{2} \mathrm{O}_{3}\{104\}$ and $\mathrm{Cr}_{2} \mathrm{O}_{3}\{104\}$ peaks compared to the $\gamma$-Ni $\{111\}$ peak for above-mentioned oxidized samples.

hours). The identification of the oxidation kinetics and related aluminum consumption is highly important both for short- and longterm oxidation for further prediction of the InCF event. Material, technical and mechanistic issues are addressed in the following sections.

\subsection{Identification of the oxidation behavior and time to InCF}

The oxidation kinetics of the MCrAlY samples were evaluated using both mass gain (Fig. 1) and oxide thickness data (Fig. 10). A direct comparison between the two types of data can be made by converting oxide thicknesses into equivalent mass. Assuming that the $\mathrm{Al}_{2} \mathrm{O}_{3}$ is compact and exempt of pores, the mass gain that corresponds to the growth of a thickness $\xi_{\mathrm{Al}_{2} \mathrm{O}_{3}}$ of $\mathrm{Al}_{2} \mathrm{O}_{3}$ is given by:

$\frac{\Delta m(t)}{S}=3 \cdot \frac{M_{\mathrm{O}}}{M_{\mathrm{Al}_{2} \mathrm{O}_{3}}} \cdot \rho_{\mathrm{Al}_{2} \mathrm{O}_{3}} \cdot \xi_{\mathrm{Al}_{2} \mathrm{O}_{3}}$

with $M_{\mathrm{Al}_{2} \mathrm{O}_{3}}$ and $\rho_{\mathrm{Al}_{2} \mathrm{O}_{3}}$ the molar mass and density of $\mathrm{Al}_{2} \mathrm{O}_{3}$. The mass gains obtained from oxide scale thicknesses measured on the $\sim 238 \mu \mathrm{m}$ thick samples are plotted along with the TGA data from the $227 \mu \mathrm{m}$-thick sample in Fig. 13(a).

The mass gains estimated from thickness measurements are lower than those directly measured by TGA. This difference presumably arises from oxidation within the bulk of the MCrAlY material, in intersplat regions (see Figs. 7 and 8 from Ref. [33]). While not included in external scale thicknesses, intersplat oxidation contributes to the mass gain, and in turn to Al consumption [34,26,35-39,33]. As a first approximation, its contribution can be estimated as the difference between both sets of results. It is seen to gradually decrease over the course of oxidation, as it represents about $46 \%, 37 \%, 27 \%$, and $12 \%$ of the mass gain for oxidation times of 20, 50, 100 and $250 \mathrm{~h}$, respectively.

Intersplat oxidation causes the oxidation behavior of the APSprocessed MCrAlY material to deviate from purely parabolic kinetics. A defect-free material would tend toward the kinetics obtained from thickness measurements. It is noted that the latter also exhibits a subparabolic behavior $(n=2.5$ in a power law, i.e., between parabolic and cubic kinetics). This deviation likely finds its source in microstructural evolutions of the $\mathrm{Al}_{2} \mathrm{O}_{3}$ [40]: at $1150{ }^{\circ} \mathrm{C}, \mathrm{Al}_{2} \mathrm{O}_{3}$ grain growth becomes significant, while scale growth still primarily occurs by grain boundary diffusion. This tends to accelerate the decrease of the oxidation rate, i.e., to produce sub-parabolic kinetics. The oxidation kinetics may also be affected by the initial formation of metastable $\mathrm{Al}_{2} \mathrm{O}_{3}(\theta$ - and $\gamma-\mathrm{Al}_{2} \mathrm{O}_{3}$ ), which grow orders of magnitude faster than $\alpha-\mathrm{Al}_{2} \mathrm{O}_{3}$ [41-45], although their presence at $1150{ }^{\circ} \mathrm{C}$ would be short-lived [46]. The size of the phase domains in the $\beta / \gamma$ microstructure is also reported to affect the formation of transition oxides in the early stages $[47,48]$.

The time at which InCF occurs can be predicted provided that a model describing the consumption kinetics of $\mathrm{Al}$ is available. A good fit of the TGA data recorded with the $227 \mu \mathrm{m}$-thick sample oxidized under flowing air can be obtained using either a power law,

$\frac{\Delta m(t)}{S}=\sqrt[n]{k_{n} \cdot t}$,

with $n=3.9$ for $t>2.5 \mathrm{~h}$, or a logarithmic law,

$\frac{\Delta m(t)}{S}=k_{l 1} \cdot \ln \left(k_{l 2} \cdot t+1\right)$,

with a single set of constants $k_{l 1}$ and $k_{l 2}$ for the whole duration of the experiment (Fig. 13(a)). On the other hand, scale thickening kinetics measured on the $\sim 238 \mu \mathrm{m}$-thick samples are best described by a power law (Eq. (4)) with $n=2.5$. The adjusted values of the parameters for both models are reported in Table 2 .

Alumina fails when the sample's $\mathrm{Al}$ is fully consumed (Figs. 3 and 11). Using Eq. (2), the corresponding mass gain, $\Delta m\left(t_{\text {InCF }}\right)$, can be expressed as a function of the initial $\mathrm{Al}$ mass:

$\frac{1}{M_{\mathrm{O}}} \frac{\Delta m\left(t_{\mathrm{InCF}}\right)}{S}=\frac{3}{2 \cdot M_{\mathrm{Al}}} \frac{m_{\mathrm{Al}}^{0}}{S}$

Given the dimensions of ultrathin samples, the base area is about half the surface area: $A \approx S / 2$. For a given oxidation rate law, the time to InCF can thus be expressed as a function of the initial sample thickness. One obtains:

$t_{\mathrm{InCF}}=\frac{1}{k_{n}}\left(\frac{3 \cdot M_{\mathrm{O}}}{4 \cdot M_{\mathrm{Al}}} \cdot \rho_{\mathrm{MCrAIY}} \cdot \xi_{\mathrm{MCrAlY}} \cdot w_{\mathrm{Al}}\right)^{n}$

for a power rate law, and:

$t_{\mathrm{InCF}}=\frac{1}{k_{\mathrm{lt}}}\left(\exp \left(\frac{3 \cdot M_{\mathrm{O}}}{4 \cdot M_{\mathrm{Al}}} \cdot \frac{\rho_{\mathrm{MCrAIY}} \cdot \xi_{\mathrm{MCrAIY}} \cdot w_{\mathrm{Al}}}{k_{\mathrm{lm}}}\right)-1\right)$

for a logarithmic rate law, where $w_{\mathrm{Al}}$ is the initial $\mathrm{Al}$ mass fraction. The evolution of $t_{\mathrm{InCF}}$ as a function of the initial thickness of the MCrAlY sample is plotted in Fig. 13(b) for the different models. Improper identification of the oxidation kinetics for short- and long-term exposures can lead to important difference in the estimated $t_{\text {InCF }}$ for ultrathin products. For instance, $t_{\mathrm{InCF}}$ is about 3.5 times greater when estimated from a model adjusted on the scale thickness data, versus TGA data, for a 

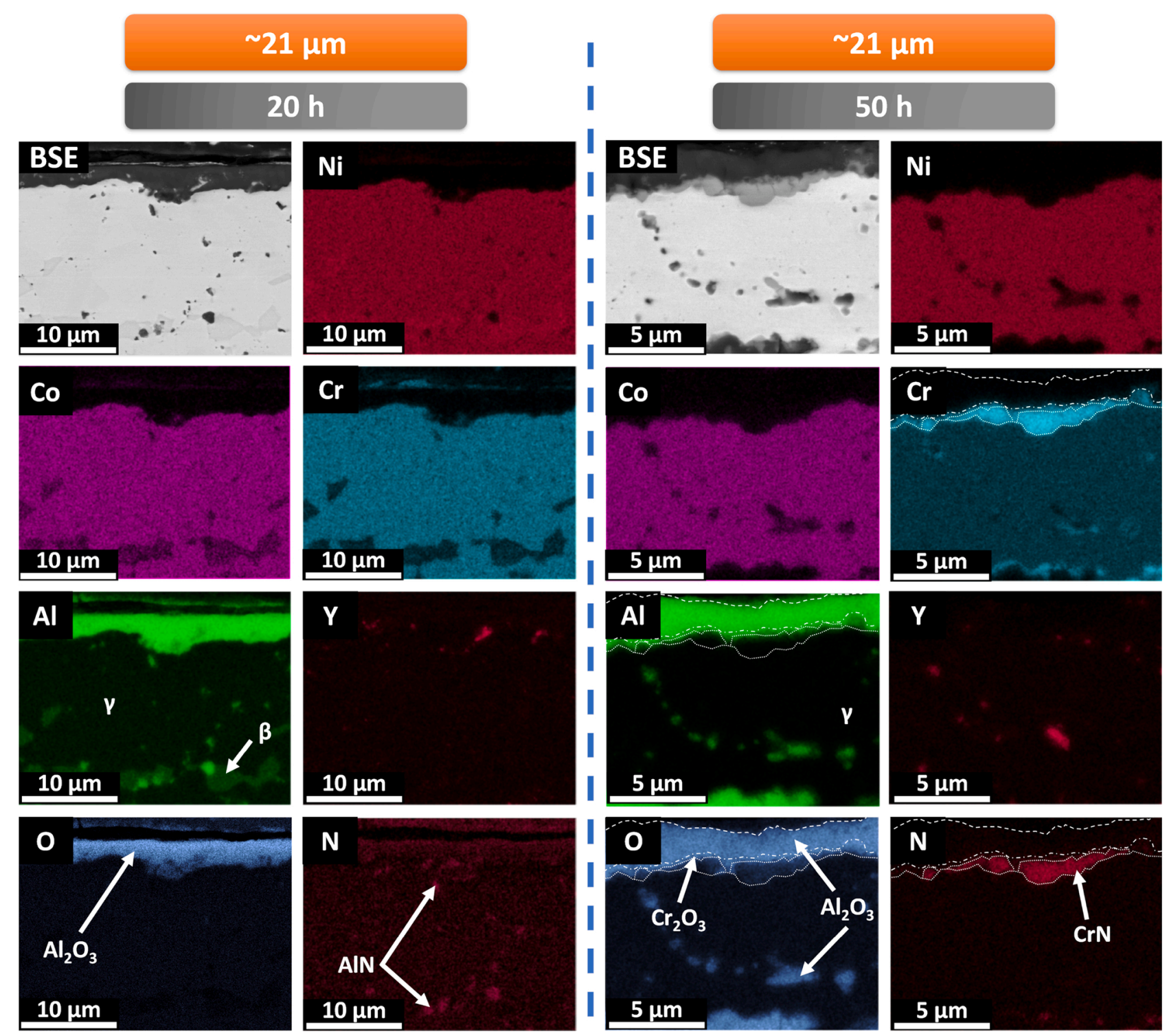

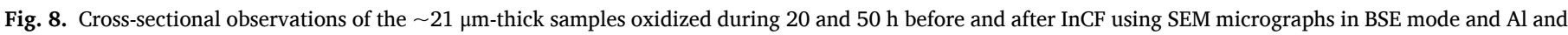

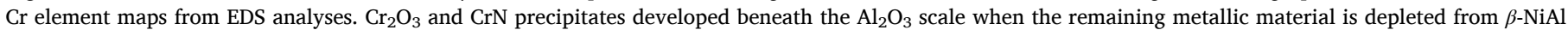
phases and AlN precipitates. White arrows on the right of the $\mathrm{Cr}$ element maps show the initial thickness of the sample before oxidation.

$\sim 21 \mu \mathrm{m}$-thick sample, or 2.4 times greater for a $\sim 31 \mu \mathrm{m}$-thick sample. The difference progressively decreases with the sample thickness for samples thinner than $45 \mu \mathrm{m}$. For thicker samples, on the contrary, $t_{\mathrm{InCF}}$ estimated from thickness data is lower than the one obtained from TGA data, and the difference gradually increases with the sample thickness.

Estimations of $t_{\text {InCF }}$ based on external scale thickness measurements miss the contribution of intersplat oxidation in the $\mathrm{Al}$ mass balance, and are therefore less suitable than estimations based on mass gain data. In terms of kinetics modeling, the logarithmic rate law has no physical justification here, but offers a good description of the TGA data over the whole course of the $300 \mathrm{~h}$ experiment with a single set of parameters. On the other hand, a power rate law only gives a good fit to the TGA data after a transition regime $(t=2.5 \mathrm{~h})$. The prediction of $t_{\text {InCF }}$ is based on the consumption of $\mathrm{Al}$ integrated from the start of oxidation. Therefore, the logarithmic model is found to be better suited to the purpose of estimating $t_{\text {InCF. }}$.

In the present study, samples thinner than $60 \mu \mathrm{m}$ exhibited InCF in the investigated $t<300 \mathrm{~h}$ window, as reported in Figs. 2 and 3 . Experimental and calculated values of $t_{\text {InCF }}$ are compared for the $\sim 21$ $\mu \mathrm{m}$ - and $\sim 31 \mu \mathrm{m}$-thick samples in Fig. 14 . Tens of hours were needed for both sample sizes for InCF to spread over the whole surface. Therefore, different categories have been defined in Fig. 14 depending on the progress of InCF: no InCF, less and more than $10 \%$ of the sample surface affected by InCF. Experimental results are in good agreement with the logarithmic model adjusted on TGA data.

It is reminded that the time to InCF estimated from a model adjusted on oxide thickness data corresponds to a defect-free sample, without oxide intrusions. A defect-free sample would be estimated to withstand 3.6 times, 2.5 times, and 1.4 times longer than this APS-processed sample for an initial thickness of $20 \mu \mathrm{m}, 30 \mu \mathrm{m}$, and $40 \mu \mathrm{m}$, respectively. Intersplat oxidation is highly process-dependent and can be significantly avoided using additional treatments to close intersplat pores and channels [49] or by improving parameters of the deposition/projection processes and post-heat treatment $[36,39]$. Based on the present estimations, i.e., considering only oxidation-induced InCF, improving process parameters so as to reduce intersplat oxidation could potentially offer significant gains in coating lifetime. 


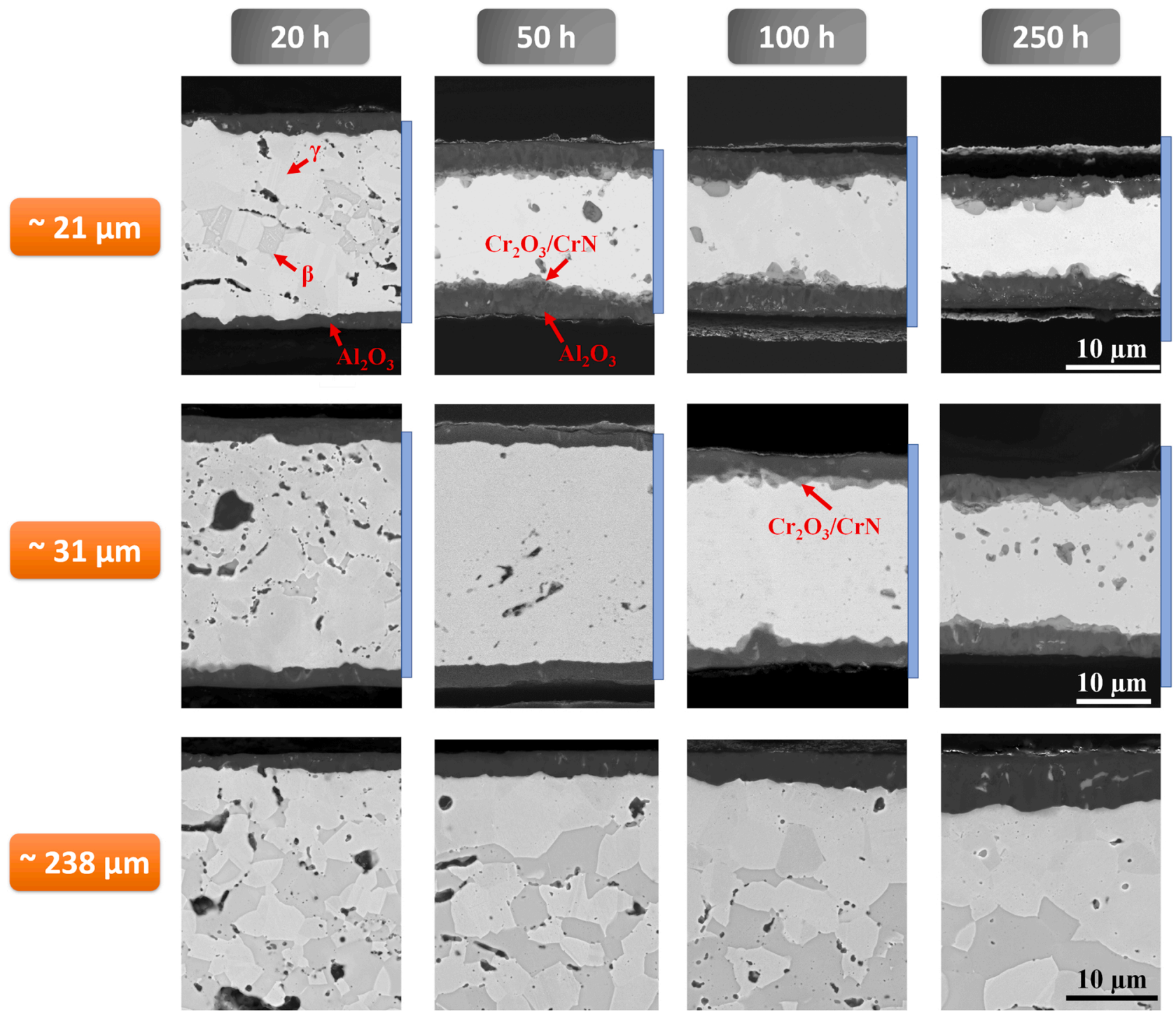

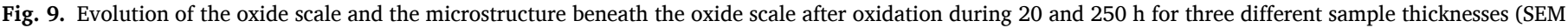
observations in a backscaterred electron mode). Blue boxes on the right of the micrographs show the initial thickness of the sample before oxidation.

\subsection{Ultrathin sample preparation and time to InCF}

InCF was found to take hours and even tens of hours to fully affect ultrathin samples (Figs. 2 and 3). As noticed in Fig. 14, slight changes in sample thickness could highly affect the time at which this change in oxidation products occurs. In the present paper, ultrathin samples were polished using a precision jig to control geometrical tolerances of the samples and more precisely the thickness variation. Centimeter-size but micrometer-thick samples are needed to accurately measure the evolution of the mass gain due to oxidation. However, the preparation of such samples is challenging and leads to local variation in thickness. This local variation in thickness were measured to be $\pm 2-3 \mu \mathrm{m}$ over the whole surface sample, as reported in Ref. [29,50]. The variation in thickness could arise from a mismounting of the samples on the glass support (parallelism and curvature), a defect when grinding of the precision jig, edge effects leading to rounded edges. The thickness distribution function of a sample can thus vary from one sample to another. This distribution function was not assessed prior to oxidation for all the samples due to technical reasons and only the average thickness was taken into account. For the sake of simplicity, the thickness of the samples is considered to follow a normal distribution with a standard deviation of $1 \mu \mathrm{m}$. Therefore, the probability density function can be expressed as:

$f\left(\xi_{\mathrm{MCrAIY}}\right)=\frac{1}{\sigma \sqrt{2 \pi}} \exp \left(-\frac{\left(\xi_{\mathrm{MCrAIY}}-\overline{\xi_{\mathrm{MCrAIY}}}\right)^{2}}{2 \sigma^{2}}\right)$

with $\xi_{M C r A l Y}$ the local thickness of the sample, $\overline{\xi_{\text {MCrAIY }}}$ the average thickness, and $\sigma$ the standard deviation in thickness $(1 \mu \mathrm{m})$. The cumulative density function can thus be expressed as follows:

$F\left(\xi_{\mathrm{MCrAIY}}\right)=\frac{1}{2}\left[1+\operatorname{erf}\left(\frac{\xi_{\mathrm{MCrAIY}}-\overline{\xi_{\mathrm{MCrAIY}}}}{\sigma \sqrt{2}}\right)\right]$

Assuming that the lateral extension of the InCF on the sample surface is not driven by a nucleation/growth phenomenon and only depends on the local thickness of the sample, $\xi_{M C r A l Y}$ can be expressed as a function of $t_{\text {InCF }}$ using Eq. (8):

$\xi_{\mathrm{MCrAIY}}=\frac{4 \cdot M_{\mathrm{Al}} \cdot k_{\mathrm{lm}}}{3 \cdot M_{\mathrm{O}} \cdot \rho_{\mathrm{MCrAIY}} \cdot w_{\mathrm{Al}}} \cdot \ln \left(k_{\mathrm{lt}} \cdot t_{\mathrm{InCF}}+1\right)$

A cumulative density function of InCF time, $F\left(t_{\text {InCF }}\right)$, can then be obtained by substituting Eq. (11) in Eq. (10). This function $F\left(t_{\mathrm{InCF}}\right)$ is a model of the surface fraction of the sample affected by InCF. The experimental and modeled fractions of InCF are plotted as a function of 

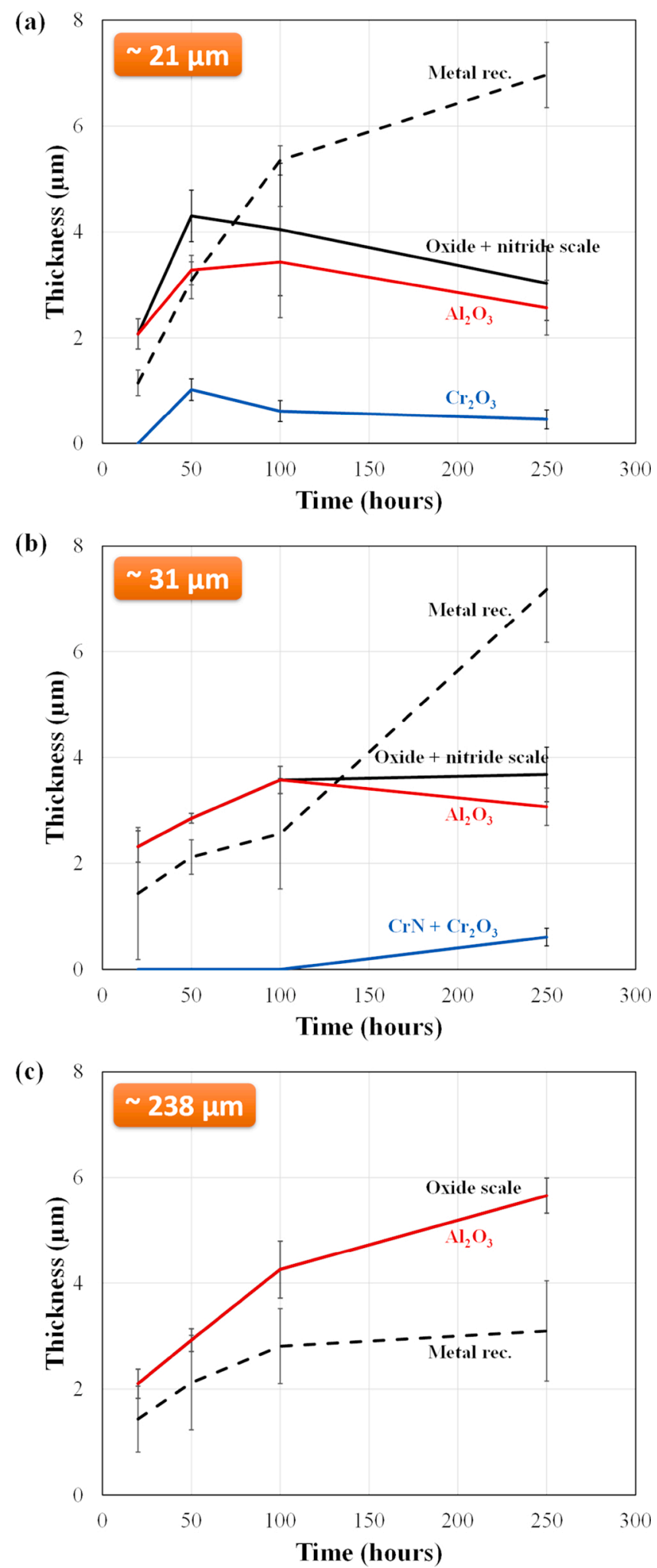

Fig. 10. Evolution of the thickness of the oxide scale and the extension of the metal recession zone as a function of the time for the $\sim 21 \mu \mathrm{m}$-thick samples, $\sim 31 \mu \mathrm{m}$-thick samples and $\sim 238 \mu \mathrm{m}$-thick samples.

time for different sample thicknesses in Fig. 15. Experimental results and prediction are in good agreement. The time required for a given surface coverage to be attained is seen to be quite sensitive to the sample thickness, as a $\pm 2-3 \mu \mathrm{m}$ variation on a $\sim 30 \mu \mathrm{m}$-thick sample results in a $\sim 70 \mathrm{~h}$ shift.
An additional source of variability in the evolution of the surface coverage of post-InCF material is found in the coating microstructure. As mentioned earlier, intersplat oxide intrusions are present in the specimens due to oxygen ingress in intersplat channels during high temperature exposure (e.g. Fig. 8 from Ref. [33]). Intersplat oxidation consumes Al locally; this affects the onset of InCF locally, and therefore contributes to variability in the overall $t_{\mathrm{InCF}}$ distribution. Investigations of $\mathrm{Al}_{2} \mathrm{O}_{3}$ failure in thin foils of commercial alloys have been reported in the literature, e.g. in Refs. [21,23,24,51,18,52-55]. In these studies, the samples used for oxidation testing were primarily produced by rolling, as they would be in a number of practical applications. Rolling provides good control over the sample dimensions, but also produces particular microstructures (with strong morphological and crystallographic texture), which may not necessarily be wanted, depending on the application. In the present study, the samples were prepared by gentle mechanical polishing. This technique has a lesser effect on the alloy microstructure, and can therefore be used to study a wide variety of materials. The samples used here were centimeter-size with thicknesses down to $15 \pm 2-3 \mu \mathrm{m}$. A yet better control of the thickness distribution would help future work on protective oxide failure and its numerical simulation.

\subsection{InCF: Mechanisms and kinetics}

The criterion to activate InCF was found to correspond to the full consumption of the aluminum present in the MCrAlY material (Fig. 11). At this stage, the microstructure of the MCrAlY material is fully $\gamma$. No remaining $\beta$ phase was observed in the bulk of the sample (Figs. 8 and 9). As aforementioned, both external oxidation and oxidation in the volume of the material were observed to participate in the aluminum consumption. Prior to InCF, the external oxide scale was constituted of $\alpha-\mathrm{Al}_{2} \mathrm{O}_{3}$ with few islets of $(\mathrm{Ni}, \mathrm{Co}) \mathrm{Al}_{2} \mathrm{O}_{4}$ spinels sparsely distributed at the external surface (Fig. 4). The external $\mathrm{Al}_{2} \mathrm{O}_{3}$ layer was found to follow a sub-parabolic oxidation behavior, i.e., lying between a parabolic and cubic oxidation behavior, as depicted in Figs. 10 and 13 (a). Internal $\mathrm{Al}_{2} \mathrm{O}_{3}$ dispersoids and $\mathrm{AlN}$ precipitates were also found in intersplat regions. After InCF, the reaction microstructure evolves, as $\mathrm{Cr}_{2} \mathrm{O}_{3}$ develops beneath the $\mathrm{Al}_{2} \mathrm{O}_{3}$ scale and $\mathrm{CrN}$ forms beneath the $\mathrm{Cr}_{2} \mathrm{O}_{3}$ (Figs. 8 and 9), while AlN is no longer present in the coating. Some $\mathrm{Al}$ is found in the newly formed $\mathrm{Cr}_{2} \mathrm{O}_{3}$ (Fig. 11 and supplementary materials). Indeed, $\mathrm{Cr}_{2} \mathrm{O}_{3}$ and $\mathrm{Al}_{2} \mathrm{O}_{3}$ show substantial mutual miscibility above $1000{ }^{\circ} \mathrm{C}[56,57]$. Chyrkin et al. reported the formation of an (Al, $\mathrm{Cr})_{2} \mathrm{O}_{3}$ oxide beneath the external $\mathrm{Al}_{2} \mathrm{O}_{3}$ near the specimen edge and above the external $\mathrm{Al}_{2} \mathrm{O}_{3}$ in the central region of the specimen after isothermal oxidation of thin Haynes 214 foils at $1200{ }^{\circ} \mathrm{C}$ for $720 \mathrm{~h}$ [54]. They also reported the formation of $(\mathrm{Al}, \mathrm{Cr})_{2} \mathrm{O}_{3}$ beneath the external $\mathrm{Al}_{2} \mathrm{O}_{3}$ scale during thermal cycling for a shorter exposure time $(500 \mathrm{~h})$ in regions subjected to oxide cracking, an illustration of the accelerating role of mechanical damage on $\mathrm{Al}_{2} \mathrm{O}_{3}$ failure (MICF). While the formation of a $\mathrm{Cr}_{2} \mathrm{O}_{3}$ layer beneath the $\mathrm{Al}_{2} \mathrm{O}_{3}$ scale was already reported in the literature, the formation of $\mathrm{CrN}$ precipitates at the oxide/metal interface due to InCF under isothermal oxidation at high temperature was not reported yet, to the authors' knowledge. Aluminum consumption in the alloy eventually leads to the dissolution of the AlN precipitates. This releases $\mathrm{N}$, which can then diffuse toward the alloy/scale interface to react with $\mathrm{Cr}$ and form $\mathrm{CrN}$. In addition, $\mathrm{N}$ may also come from the atmosphere, and reach the alloy/scale interface by diffusion/transport through the $\mathrm{Al}_{2} \mathrm{O}_{3}$ scale after InCF. Indeed, apparently compact $\mathrm{Al}_{2} \mathrm{O}_{3}$ scales have been observed to lose their protective properties and become permeable to $\mathrm{N}$ after chemical failure $[58,59]$. In addition to the formation of sub-surface $\mathrm{Cr}_{2} \mathrm{O}_{3}$ plus $\mathrm{CrN}$ precipitates, the external oxide scale slightly differs after InCF. The network of $(\mathrm{Ni}, \mathrm{Co}) \mathrm{Al}_{2} \mathrm{O}_{4}$ spinels at the external surface intensified, as illustrated in Fig. 4. Spinels were also reported for $\mathrm{Al}_{2} \mathrm{O}_{3}$-forming alloys even without the growth of the sub-surface $\mathrm{Cr}_{2} \mathrm{O}_{3}$, such as $\mathrm{Ni}(\mathrm{Al}, \mathrm{Cr})_{2} \mathrm{O}_{4},(\mathrm{Ni}, \mathrm{Co}) \mathrm{Al}_{2} \mathrm{O}_{4}$ and $(\mathrm{Ni}, \mathrm{Co})(\mathrm{Al}$, $\mathrm{Cr})_{2} \mathrm{O}_{4}$ spinels $[47,35,53,54,39]$. Furthermore, $\mathrm{NiO}$ was found to form in 


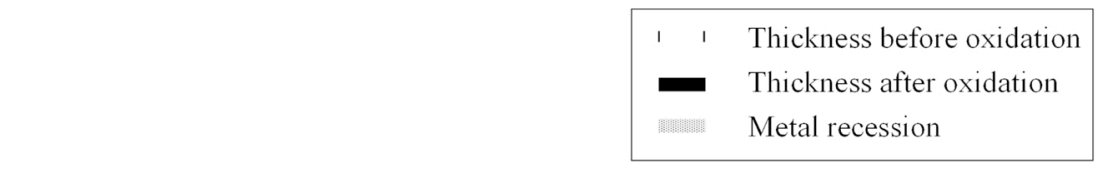

(a)

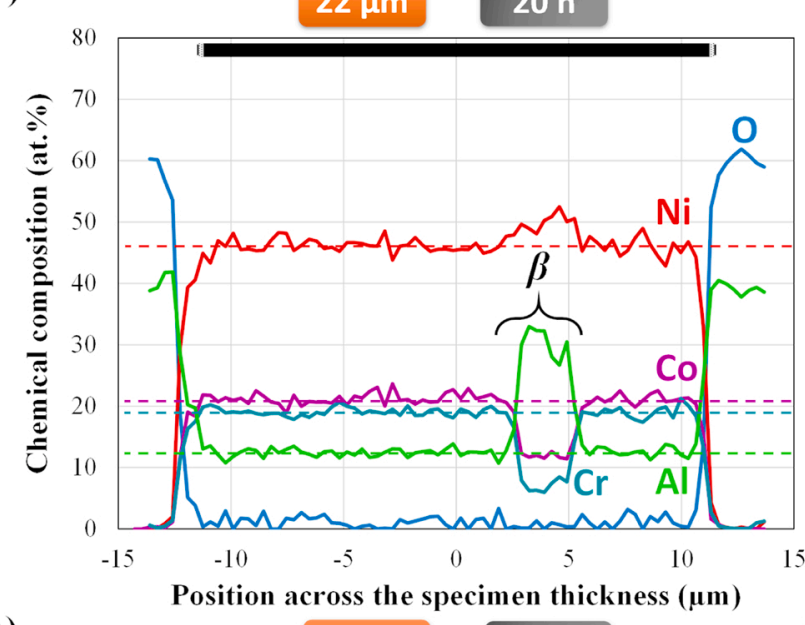

(c)

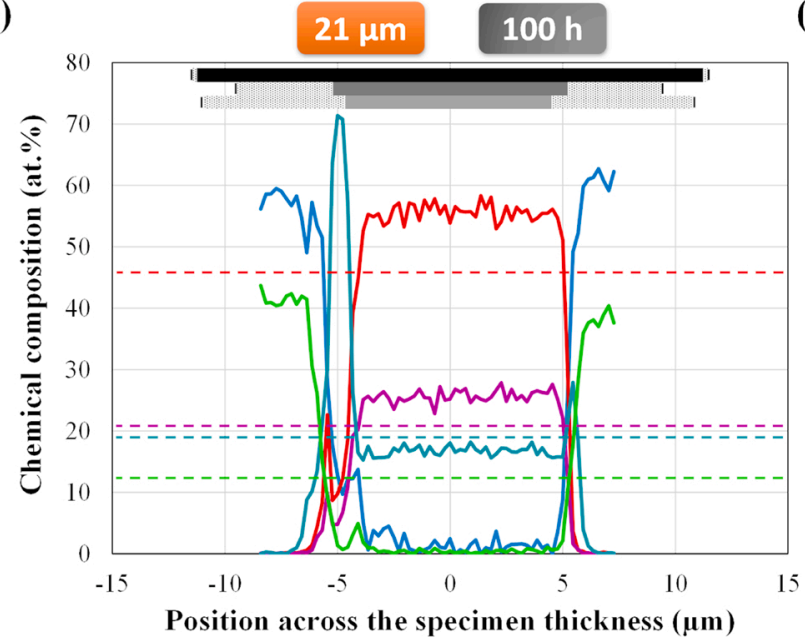

(b)

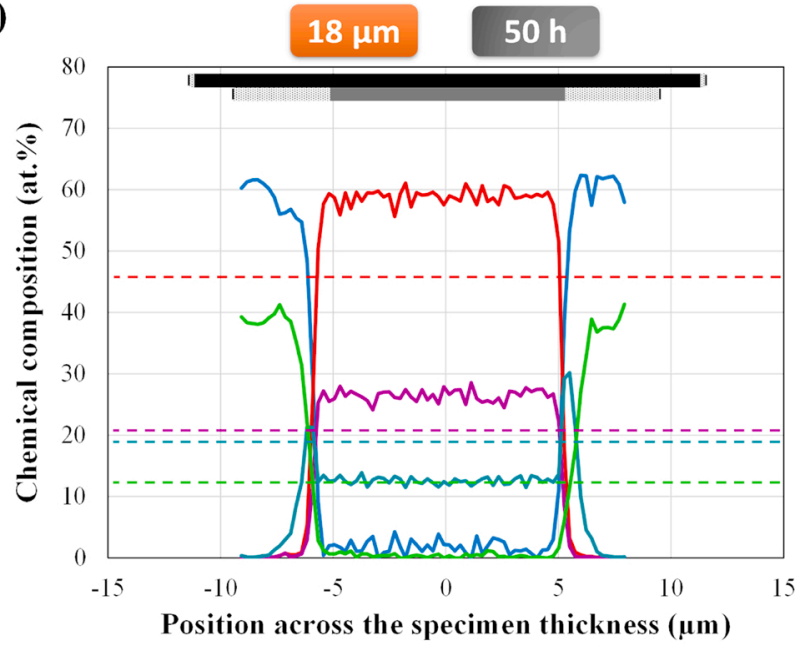

(d)

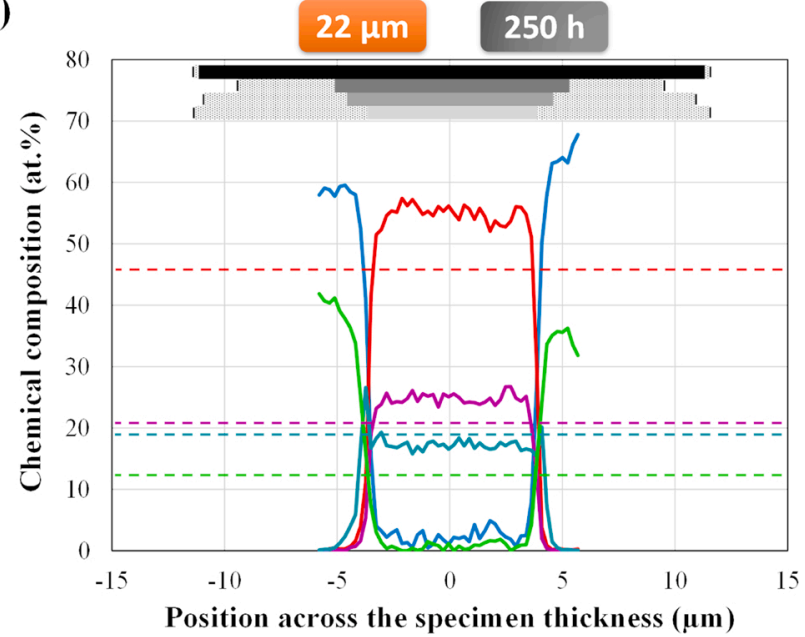

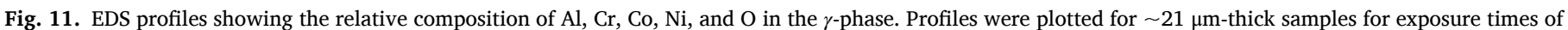

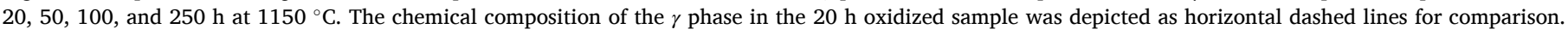

the center of $(\mathrm{Ni}, \mathrm{Co}) \mathrm{Al}_{2} \mathrm{O}_{4}$ islets as the last stage of InCF (Fig. 5). It is worth mentioning that oxide intrusion was found to develop beneath $(\mathrm{Ni}, \mathrm{Co}) \mathrm{Al}_{2} \mathrm{O}_{4}$ islets forming $\mathrm{NiO}$. Oxide intrusion, i.e., faster $\mathrm{Al}$ - then $\mathrm{Cr}$-depleted regions, could be responsible of the local InCF then breakaway. Despite being intrinsically much faster-growing oxides than $\mathrm{Al}_{2} \mathrm{O}_{3}$, the formation of oxides of $\mathrm{Cr}$, Co and Ni did not result in a marked increase of the mass gain. Indeed, in the absence of damage within the $\mathrm{Al}_{2} \mathrm{O}_{3}$ scale, the growth of the $\mathrm{Cr}_{2} \mathrm{O}_{3}$ layer and of the $(\mathrm{Ni}, \mathrm{Co}) \mathrm{Al}_{2} \mathrm{O}_{4}$ and $\mathrm{NiO}$ islets must proceed via diffusion through the $\mathrm{Al}_{2} \mathrm{O}_{3}$, and is therefore limited by $\mathrm{Al}_{2} \mathrm{O}_{3}$ diffusion properties. Similar observations have been reported for other $\mathrm{Al}_{2} \mathrm{O}_{3}$ - or $\mathrm{Cr}_{2} \mathrm{O}_{3}$-forming materials [23,24,60,52,53]. In particular, Ishii et al. reported that the mass gain associated with the growth of a sub-surface $\mathrm{Cr}_{2} \mathrm{O}_{3}$ layer after the alloy is exhausted of its $\mathrm{Al}$ follows the same oxidation kinetics as those of $\mathrm{Al}_{2} \mathrm{O}_{3}$, as long as the $\mathrm{Al}_{2} \mathrm{O}_{3}$ scale is not damaged [23]. Strehl et al. reported a decrease in the oxidation rate when $\mathrm{Cr}_{2} \mathrm{O}_{3}$ started to develop beneath an external $\mathrm{Al}_{2} \mathrm{O}_{3}$ scale [24]. Such findings support the fact that the growth of the sub-surface $\mathrm{Cr}_{2} \mathrm{O}_{3}$ layer but also the $(\mathrm{Ni}, \mathrm{Co})(\mathrm{Al}, \mathrm{Cr})_{2} \mathrm{O}_{4}$ spinels is controlled by the limited diffusion through the $\mathrm{Al}_{2} \mathrm{O}_{3}$ scale.

In the present work, the mass gain was found to progressively slow down for experiments conducted under static air, and a mass loss was recorded in experiments under air flow, after $\mathrm{InCF}$ and $\mathrm{Cr}_{2} \mathrm{O}_{3}$ formation.
This mass loss is likely to be due to $\mathrm{Cr}$ diffusion across the $\mathrm{Al}_{2} \mathrm{O}_{3}$ and $\mathrm{Cr}_{2} \mathrm{O}_{3}$ reactive volatilization [61] at the scale surface, which would be insignificant in a static atmosphere. Cr-depletion was also observed after the onset of $\mathrm{Cr}_{2} \mathrm{O}_{3}$ formation using EDS profile measurements within the MCrAlY material (Fig. 11). Ni and Co gradually decreased to participate in the spinel formation. Similar mass gain behavior were reported for other $\mathrm{Al}_{2} \mathrm{O}_{3}$ - or $\mathrm{Cr}_{2} \mathrm{O}_{3}$-forming materials, as long as the protective oxide scale remains undamaged, compact, dense and adherent [23,24,52,53].

Oxide formation is also accompanied by the metal recession due to consumption of elements participating in the growth of the oxide scale. In the present paper, the metal recession prior to InCF was found to extend less than the thickness of the oxide scale (Fig. 10). This statement is in good agreement with the Pilling-Bedworth ratio of the $\mathrm{Al}_{2} \mathrm{O}_{3}$ for NiCoCrAlY alloys. After InCF, the metal recession significantly increased and is even more important than the growth of the oxide scale. This finding is not in good agreement with a Pilling-Bedworth ratio approach since $R_{\mathrm{PB}}^{\mathrm{Cr}_{2} \mathrm{O}_{3}}$ is greater than $R_{\mathrm{PB}}^{\mathrm{Al}_{2} \mathrm{O}_{3}}$. Strehl et al. also reported a significant metal recession of thin FeCrAl foils [24]. They tried to relate this intense metal recession with the potential elongation of the sample due to creep during isothermal oxidation, stress being inherent to the growth of the oxide willing to expand more than the consumed metal. The 

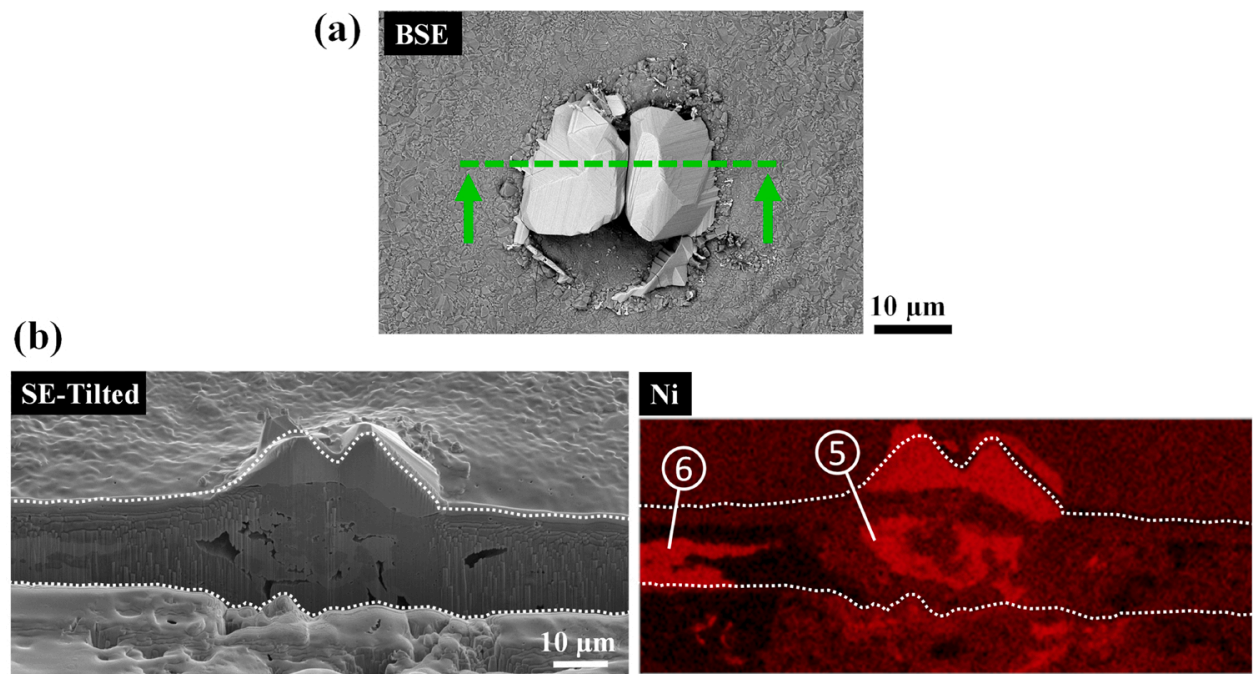

Co

$\mathrm{Cr}$
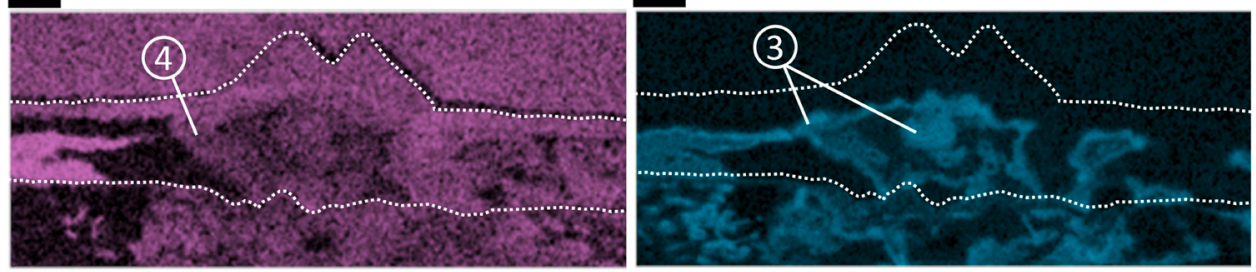

Al

o
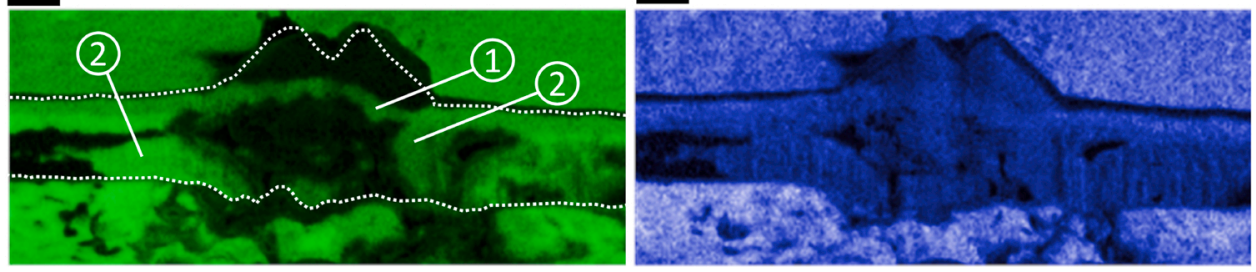

Fig. 12. SEM observation of (Ni,Co)-rich oxides as the final stage of the $\mathrm{InCF}$ growing on $(\mathrm{Ni}, \mathrm{Co}) \mathrm{Al}_{2} \mathrm{O}_{4}$ islets for this oxidation conditions and material. (a) Surface observation in backscattered electron mode (the green dashed line corresponds to the FIB section trace), (b) Micrographs in secondary electron mode and element maps of the FIB-cross-section view.
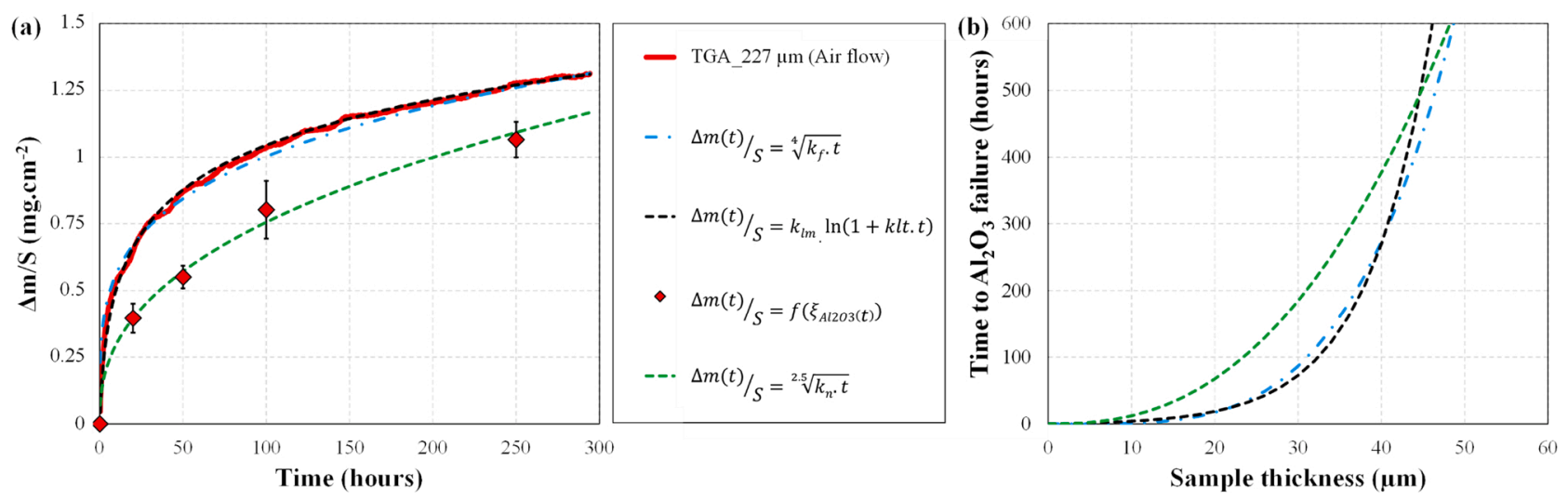

Fig. 13. (a) Comparison of oxidation kinetics based on TGA data and oxide thickness measurements, and (b) Estimation of the time to InCF based on the indicated oxidation models.

underestimation of the calculated sample thickness after oxidation in comparison with experimental results requires explanation that neither Strehl et al.'s paper nor this paper provides. In the present investigation, macrographs observations did not reveal significant size variations of the sample in the longitudinal and transversal directions during oxidation due to possible creep of the ultrathin sample. Another size effect on the oxidation of ultrathin products was also demonstrated using thin samples with different thicknesses. It is worth noting that thermal cycling generally leads to oxide spallation, thus favoring the onset of localized InCF, i.e., mechanically induced chemical failure (MICF). While ultrathin samples would be intensively affected by enhanced Al consumption due to oxide spallation, they demonstrate a high resistance 
Table 2

Parameters of the oxidation models adjusted on TGA and oxide thickness data obtained from the reference samples $(227 \mu \mathrm{m}$ - and $\sim 238 \mu$ m-thick samples).

\begin{tabular}{|c|c|c|c|c|}
\hline Data & Model & Parameters & $\begin{array}{l}\text { Reg. } \\
\text { coeff. }\left(R^{2}\right)\end{array}$ & Ref \\
\hline TGA & Power law & $n=3.9 k_{n}=1.0 \times 10^{-2} \mathrm{mg}^{4} \mathrm{~cm}^{8} \mathrm{~s}^{-1}$ & 0.986 & $\begin{array}{l}\text { Eq. } \\
(4)\end{array}$ \\
\hline TGA & Logarithmic & $\begin{array}{l}k_{l 1}=0.25 \mathrm{mg} \mathrm{cm}^{2} k_{l 2}=6.7 \times 10^{-1} \\
\mathrm{~s}^{-1}\end{array}$ & 0.996 & $\begin{array}{l}\text { Eq. } \\
(5)\end{array}$ \\
\hline$\xi_{\mathrm{Al}_{2} \mathrm{O}_{3}}$ & Power law & $\begin{array}{l}n=2.5 k_{n}=3.1 \times 10^{-1} \mu \mathrm{m}^{2.5} \mathrm{~s}^{-1} \\
\left(5.0 \times 10^{-3} \mathrm{mg}^{2.5} \mathrm{~cm}^{5} \mathrm{~s}^{-1}\right)\end{array}$ & 0.988 & Eq. \\
\hline
\end{tabular}

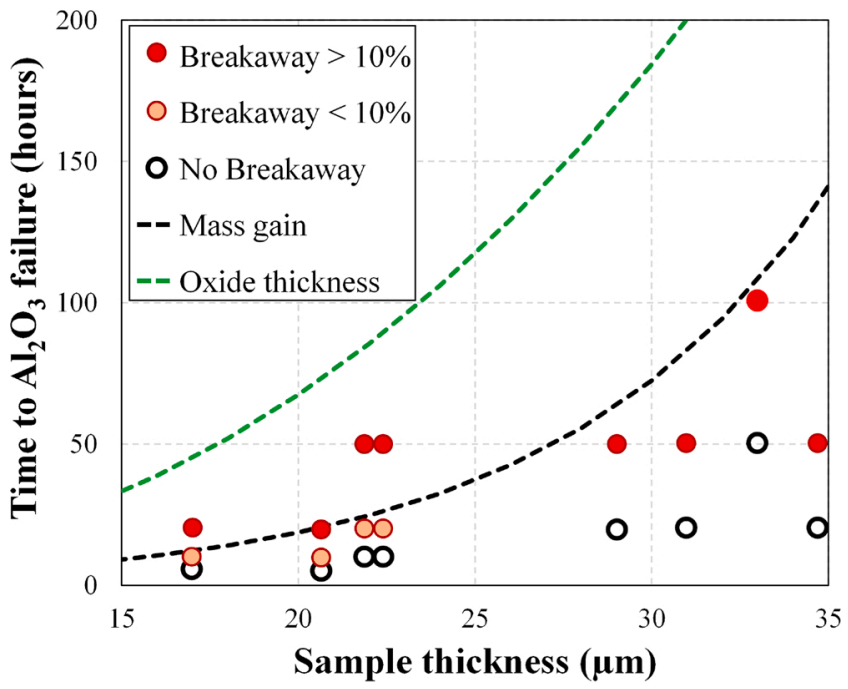

Fig. 14. Comparison between experimental and calculated time to InCF as a function of the sample thickness. The calculated values were obtained from a logarithmic model adjusted on TGA data and on a power law model adjusted on scale thickness data (both sets of data were obtained on the thicker samples, which did not undergo InCF).

to oxide spallation. Samples thinner than $60 \mu \mathrm{m}$ did not show any traces of oxide spallation while thicker samples did under interrupted oxidation tests (Fig. 2). Such resistance of ultrathin samples to oxide spallation due to strain accommodation (sample curvature for instance) was also reported by Orosz et al. [62] and Duan et al. [55]. Despite this point is in favor of ultrathin samples, i.e., thin foils, the same material used as a thin coating could yet be subjected to spallation due to the substrate stiffness. Therefore, both assessment of oxide spallation kinetics and progressive consumption of aluminum/chromium are required to better predict InCF/MICF under real service conditions. In the present study, APS-processed MCrAlY were polished to investigate the oxidation resistance of ultrathin products at high temperature. However, APS-processed MCrAlY generally presents a rough surface inherent to the deposition process. Oxidation of a rough surface can lead to different oxidation products and rates depending on the curvature of the outer surface. Onset of breakaway associated with oxide micro-cracking in rough regions was also reported $[63,64]$. This could be attributed to non-uniform consumption of $\mathrm{Y}$ and $\mathrm{Al}$ beneath the rough surfaces and repeated-cracking/re-growth of the $\mathrm{Al}_{2} \mathrm{O}_{3}$ scale during temperature cycling.

\section{Conclusion}

The oxidation resistance of an APS-processed MCrAlY material was investigated at $1150{ }^{\circ} \mathrm{C}$ using freestanding coating samples of various thicknesses. This screening technique was proposed to assess intrinsic chemical failure (InCF) of ultrathin samples for short-term oxidation testing. The following conclusions can be drawn from the present work:

- InCF occurred after the alloy was fully depleted of its $\mathrm{Al}$, and led to the formation of a $\mathrm{Cr}_{2} \mathrm{O}_{3}$ layer at the $\mathrm{Al}_{2} \mathrm{O}_{3}$-alloy interface, of subsurface $\mathrm{CrN}$ precipitates, and of $(\mathrm{Ni}, \mathrm{Co})(\mathrm{Al}, \mathrm{Cr})_{2} \mathrm{O}_{4}$ islands at the surface of the $\mathrm{Al}_{2} \mathrm{O}_{3}$.

- The mass gain did not significantly accelerate following InCF, due to the fact that the $\mathrm{Al}_{2} \mathrm{O}_{3}$ layer remained mechanically intact. The $\mathrm{Al}_{2} \mathrm{O}_{3}$ lost its protective character in that it allowed the oxidation of $\mathrm{Cr}$, Ni and $\mathrm{Co}$, but it retained a beneficial role in limiting their diffusion rate;

- The lamellar microstructure of the APS-processed material resulted in intersplat oxidation, which locally accelerated $\mathrm{Al}$ consumption and thus the occurrence of InCF. Therefore, improvements in the material microstructure could significantly delay InCF in sprayed materials;

- Intense metal recession was found after InCF without significant size variation of the external surface area;

- Ultrathin samples were less prone to oxide spallation than thicker samples, due to their higher compliance;

- The identification of the oxidation kinetics on bulk samples is necessary to well predict the time to InCF on ultrathin samples;

- The present study demonstrated the interest of using ultrathin samples to rapidly screen onset of InCF for lifetime evaluations of materials under isothermal or thermal cycling conditions.

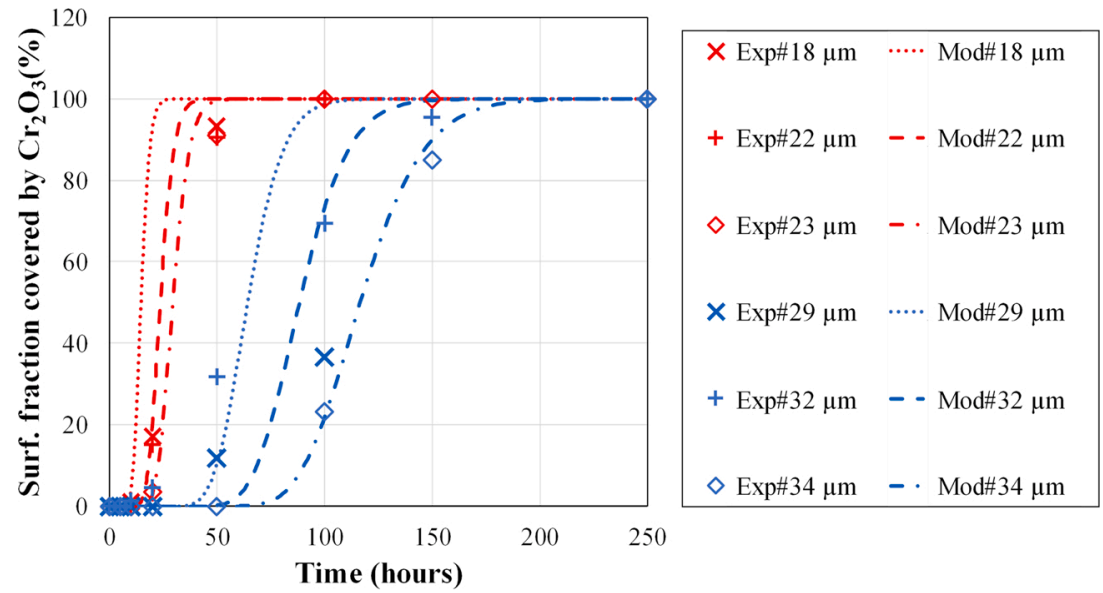

Fig. 15. Experimental and estimated fraction of InCF as a function of the oxidation time for different sample thicknesses. 


\section{Data availability}

The raw/processed data required to reproduce these findings cannot be shared at this time due to technical or time limitations.

\section{Declaration of Competing Interest}

The authors report no declarations of interest.

\section{Acknowledgements}

This work was supported by the Agence Nationale de la Recherche (ANR) [ANR-18-CE08-0003; ANR-JCJC-COMPAACT project funded from the AAPG2018]. The authors are grateful to Stephane Le Blond Du Plouy and Claudie Josse from the Raymond Castaing Microanalysis Centre (Mixed Services Unit 3623) for access to microscopy facilities and assistance. The authors are grateful to Karim CHOQUET and Geoffrey SALVI (ICA-IMT Mines Albi) and Remi ROUMIGUIER (MIDIVAL) for technical assistance.

\section{Appendix A. Supplementary data}

Supplementary data associated with this article can be found, in the online version, at https://doi.org/10.1016/j.corsci.2021.109334.

\section{References}

[1] T. Pollock, S. Tin, J. Propul. Power 22 (2006) 361-374.

[2] R. Reed, The Superalloys: Fundamentals and Applications, Cambridge University Press, 2008.

[3] D.J. Young, High Temperature Oxidation and Corrosion of Metals, 2nd ed. edition, 2016.

[4] R. Mévrel, Mater. Sci. Eng. A 120-121 (1989) 13-24.

[5] T. Rhys-Jones, Coatings for Blade and Vane Applications in Gas Turbines, 1989.

[6] S. Bose, High Temperature Coatings, 1st ed., Butterworth-Heinemann, 2007.

[7] H. Evans, M. Taylor, Proc. Inst. Mech. Eng., Part G: J. Aerospace Eng. 220 (2006) $1-10$.

[8] W. Sloof, T. Nijdam, Int. J. Mater. Res. 100 (2009) 1318-1330.

[9] D. Tejero-Martin, M. Rezvani Rad, A. McDonald, T. Hussain, J. Therm. Spray Technol. 28 (2019) 598-644.

[10] H.E. Evans, Int. Mater. Rev. 40 (1995) 1-40.

[11] T. Pollock, B. Laux, C. Brundidge, A. Suzuki, M. He, J. Am. Ceram. Soc. 94 (2011) s136-s145.

[12] H. Hindam, D.P. Whittle, Oxid. Met. 18 (1982) 245-284.

[13] A. Pineau, S.D. Antolovich, Eng. Fail. Anal. 16 (2009) 2668-2697.

[14] J.-C. Stinville, M. Echlin, P. Callahan, V. Miller, D. Texier, F. Bridier, P. Bocher, T. Pollock, Exp. Mech. 57 (2017) 1289-1309.

[15] D. Whittle, Oxid. Met. 4 (1972) 171-179.

[16] H. Evans, A. Donaldson, T. Gilmour, Oxid. Met. 52 (1999) 379-402.

[17] C. Giggins, F. Pettit, J. Electrochem. Soc. 118 (1971) 1782-1790.

[18] J. Wilber, M. Bennett, J. Nicholls, Mater. High Temp. 17 (2000) 125-132.

[19] N. Vialas, D. Monceau, Surf. Coat. Technol. 201 (2006) 3846-3851.

[20] A. Raffaitin, F. Crabos, E. Andrieu, D. Monceau, Surf. Coat. Technol. 201 (2006) 3829-3835.

[21] W. Quadakkers, K. Bongartz, Mater. Corros. 45 (1994) 232-241.

[22] S.-H. Lee, J.-W. Choi, S.-G. Kang, J. Power Sources 108 (2002) 74-85.
[23] K. Ishii, M. Kohno, S. Ishikawa, S. Satoh, Mater. Trans. 38 (1997) 787-792.

[24] G. Strehl, D. Naumenko, H. Ai-Badairy, L. Rodriguez Lobo, G. Borchardt, G. Tatlock, W. Quadakkers, Mater. High Temp. 17 (2000) 87-92.

[25] F. Xie, Y. Sun, D. Li, Y. Bai, W. Zhang, Ceram. Int. 45 (2019) 11353-11361.

[26] H. Evans, M. Taylor, Oxid. Met. 55 (2001) 17-34.

[27] E.P. Busso, H.E. Evans, Z.Q. Qian, M.P. Taylor, Acta Mater. 58 (2010) 1242-1251.

[28] T.J. Nijdam, W.G. Sloof, Acta Mater. 56 (2008) 4972-4983.

[29] D. Texier, D. Monceau, J.-C. Salabura, R. Mainguy, E. Andrieu, Mater. High Temp. 33 (2016) 325-337.

[30] Praxair Surface Technologies, MCrAlY, 2019.

[31] D. Texier, D. Monceau, Z. Hervier, E. Andrieu, Surf. Coat. Technol. 307 (2016) $81-90$.

[32] J. Schindelin, I. Arganda-Carreras, E. Frise, V. Kaynig, M. Longair, T. Pietzsch, S. Preibisch, C. Rueden, S. Saalfeld, B. Schmid, J.-Y. Tinevez, D. James White, V. Hartenstein, K. Eliceiri, P. Tomancak, A. Cardona, Nat. Methods 9 (2012) 676-682.

[33] D. Texier, C. Cadet, T. Straub, C. Eberl, V. Maurel, Metal. Mater. Trans. 51 (2020) 2766-2777.

[34] F. Belzunce, V. Higuera, S. Poveda, Mater. Sci. Eng. A 297 (2001) 162-167.

[35] W.R. Chen, X. Wu, B.R. Marple, P.C. Patnaik, Surf. Coat. Technol. 197 (2005) $109-115$.

[36] M. Shibata, S. Kuroda, H. Murakami, M. Ode, M. Watanabe, Y. Sakamoto, Mater. Trans. 47 (2006) 1638-1642.

[37] D. Seo, K. Ogawa, Y. Suzuki, K. Ichimura, T. Shoji, S. Murata, Appl. Surf. Sci. 255 (2008) 2581-2590.

[38] K. Ma, J. Schoenung, Surf. Coat. Technol. 205 (2011) 5178-5185.

[39] G.-H. Meng, B.-Y. Zhang, H. Liu, G.-J. Yang, T. Xu, C.-X. Li, C.-J. Li, Surf. Coat. Technol. 347 (2018) 54-65.

[40] D. Naumenko, B. Gleeson, E. Wessel, L. Singheiser, W. Quadakkers, Metall. Mater. Trans. A: Phys. Metall. Mater. Sci. 38A (2007) 2974-2983.

[41] G.C. Rybicki, J.L. Smialek, Oxid. Met. 31 (1989) 275-304.

[42] M.W. Brumm, H.J. Grabke, Corros. Sci. 33 (1992) 1677-1690.

[43] W. Brandl, H. Grabke, D. Toma, J. Krüger, Surf. Coat. Technol. 86-87 (1996) 41-47.

[44] D. Toma, W. Brandl, U. Köster, Surf. Coat. Technol. 120-121 (1999) 8-15.

[45] H. Choi, B. Yoon, H. Kim, C. Lee, Surf. Coat. Technol. 150 (2002) 297-308.

[46] D. Garriga-Majo, B. Shollock, D. McPhail, R. Chater, J. Walker, Int. J. Inorg. Mater. 1 (1999) 325-336.

[47] S. Sacré, U. Wienstroth, H. Feller, L. Thomas, J. Mater. Sci. 28 (1993) 1843-1848.

[48] Y. Chen, X. Zhao, P. Xiao, Acta Mater. 159 (2018) 150-162.

[49] Y. Wu, G. Zhang, Z. Feng, B. Zhang, Y. Liang, F.J. Liu, Surf. Coat. Technol. 138 (2001) 56-60.

[50] D. Texier, Mesure et évolution des gradients de propriétés mécaniques dans le système superalliages à base de nickel MC2 revêtu MCrAlY, Ph.D. thesis, Université de Toulouse (France), 2013.

[51] H. Al-Badairy, G. Tatlock, M. Bennett, Mater. High Temp. 17 (2000) 101-107.

[52] D. Young, A. Chyrkin, W. Quadakkers, Oxid. Met. 77 (2012) 253-264.

[53] D. Young, A. Chyrkin, J. He, D. Grüner, W. Quadakkers, Oxid. Met. 79 (2013) $405-427$.

[54] A. Chyrkin, N. Mortazavi, M. Halvarsson, D. Grüner, W. Quadakkers, Corros. Sci. 98 (2015) 688-698.

[55] R. Duan, A. Jalowicka, K. Unocic, B. Pint, P. Huczkowski, A. Chyrkin, D. Grüner, R. Pillai, W. Quadakkers, Oxid. Met. 87 (2017) 11-38.

[56] D. Roy, R. Barks, Nat. Phys. Sci. 235 (1972) 118-119.

[57] K. Jacob, J. Electrochem. Soc. 125 (1978) 175-179.

[58] S. Dryepondt, A. Rouaix-Vande Put, B. Pint, Oxid. Met. 79 (2013) 627-638.

[59] T. Gheno, B. Gleeson, Oxid. Met. 86 (2016) 385-406.

[60] E. Fedorova, D. Monceau, D. Oquab, Corros. Sci. 52 (2010) 3932-3942.

[61] C. Tedmon, J. Electrochem. Soc. 113 (1966) 766.

[62] R. Orosz, U. Krupp, H.-j. Christ, D. Monceau, Oxid. Met. 68 (2007) 165-176.

[63] D. Naumenko, V. Shemet, L. Singheiser, W. Quadakkers, J. Mater. Sci. 44 (2009) 1687-1703.

[64] M. Gupta, R. Eriksson, U. Sand, P. Nylén, Surf. Coat. Technol. 271 (2015) 181-191. 